\title{
Stratigraphic profiling, slip surface detection, and assessment of remolding in sensitive clay landslides using the CPT
}

\author{
Joshua J. Potvin, David Woeller, James Sharp, and W. Andy Take
}

\begin{abstract}
A multi-year cone penetration testing program was conducted at a landslide subject to episodic retrogression in Mud Creek, Ottawa, to assess whether a hand-operated mobile cone penetration test (CPT) could yield new insights into the current degree of remolding under progressive failure in metastable areas of a landslide where conventional tracked rigs are unable to gain access. The mobile CPT rig permitted tests to be performed through the entire thickness of the Champlain Sea deposit at a penetration rate of $0.5 \mathrm{~cm} / \mathrm{s}$, with similar results to tests performed at the standard $2 \mathrm{~cm} / \mathrm{s}$. Measurements of pore pressure varied considerably with cone size, with the magnitude of pore pressure response decreasing with cone size. The elevation of the slip surface was identified in the tip resistance as the point of transition between the remolded soil above the slip surface and the intact soil below the slip surface, whereas a further $0.5 \mathrm{~m}$ of penetration was required to elevate pore pressures to values indicative of the intact soil behaviour. In situ measurements of shear strength of corresponding layers between the intact and remolded profiles to be compared indicated that the soil above the slip surface had remolded to $50 \%$ of its fully remolded strength.
\end{abstract}

Key words: CPT, in situ testing, sensitive clay, landslides.

Résumé : On a mené un programme pluriannuel de vérification de la pénétration du cône sur un glissement de terrain assujetti à une rétrogression épisodique dans le ruisseau Mud, à Ottawa, pour déterminer si un l'essai de pénétration au cône (CPT) mobile à commande manuelle pouvait apporter de nouvelles connaissances concernant le degré actuel de remodelage en cas de rupture progressive dans les zones métastables d'un glissement de terrain auxquelles les appareils à chenilles conventionnels ne peuvent accéder. L'appareil mobile de CPT a été utilisé pour effectuer des tests sur toute l'épaisseur du dépôt de la mer de Champlain à une vitesse de pénétration de $0,5 \mathrm{~cm} / \mathrm{s}$, et a donné des résultats similaires aux tests effectués à la vitesse standard de $2 \mathrm{~cm} / \mathrm{s}$. Les résultats des mesures de la pression interstitielle ont varié considérablement. Les mesures de la pression interstitielle variaient considérablement avec la taille du cône, l'ampleur de la réponse de la pression interstitielle diminuant avec la taille du cône. L'élévation de la surface de glissement a été identifiée dans la résistance de pointe comme le point de transition entre le sol remodelé au-dessus de la surface de glissement et le sol intact sous la surface de glissement, alors qu'une pénétration supplémentaire de $0,5 \mathrm{~m}$ était nécessaire pour élever les pressions de pore à des valeurs indicatives du comportement du sol intact. Les mesures in situ de la résistance au cisaillement des couches correspondantes entre les profils intacts et remoulés à comparer ont révélé que le sol au-dessus de la surface de glissement avait été remoulé à $50 \%$ de sa résistance entièrement remoulée. [Traduit par la Rédaction]

Mots-clés : CPT, essais in situ, argile sensible, glissements de terrain.

\section{Introduction}

Cone penetration testing (CPT) is the primary in situ site characterisation technique supporting post-failure investigations and back analyses of landslides in sensitive clays such as the Champlain Sea Clay. This tool provides detailed information on the stratigraphic profile, elevations of slip surfaces, and profiles of intact and remolded strength (e.g., Locat et al. 2017). The factors affecting the use of CPT techniques to infer each of these pieces of evidence are discussed in turn, using Fig. 1 as a reference.

In traditional CPT stratigraphic profiling, measurements of cone tip resistance, pore pressure, and shaft friction captured at the prescribed standard penetration rate of $2 \mathrm{~cm} / \mathrm{s}$ are used to calculate soil behaviour type (e.g., Robertson 1990) at centimetric resolution. In a forensic analysis of a sensitive clay landslide, higher resolution (i.e., millimetric scale) profiles are of interest as the cone response to the inherent slight textural changes within the sensitive clay (i.e., bands and (or) varves) may be muted in soil layers affected by destructurisation. A more detailed stratigraphic profile may, at a minimum, help identify regions of the landslide profile that have been subject to remolding and may in certain circumstances provide a valuable in situ tool to help identify the sequence of formation of horsts and grabens in the case of lateral spreads. For example, Locat et al. (2017) made use of four trenches dug in the debris to layering to gain a better understanding of the dislocation mechanism of the soil mass. Cone testing that provides in

Received 12 March 2019. Accepted 1 January 2021.

J.J. Potvin and W.A. Take.* Department of Civil Engineering, Queen's University, Kingston, ON K7L 3N6, Canada.

D. Woeller and J. Sharp. ConeTec Investigations Ltd., 12140 Vulcan Way, Richmond, BC V6V 1J8, Canada.

Corresponding author: W. Andy Take (email: andy.take@queensu.ca).

*W. Andy Take served as an Associate Editor at the time of manuscript review and acceptance; peer review and editorial decisions regarding this manuscript were handled by Abouzar Sadrekarimi.

() 2021 The Author(s). This work is licensed under a Creative Commons Attribution 4.0 International License (CC BY 4.0), which permits unrestricted use, distribution, and reproduction in any medium, provided the original author(s) and source are credited. 
Fig. 1. Stratigraphic profiling and slip surface identification in banded or varved clays: (a) length scales of tip cone resistance and $u_{2}$ pore pressure in contrast to length scales of varves or bands and thickness of disturbed soil along shear surface and (b) interpretation of alternating clay and silt-rich layer pairs to form an individual varve. [Colour online.]

\section{a) Length scales of CPT stratigraphic profiling}

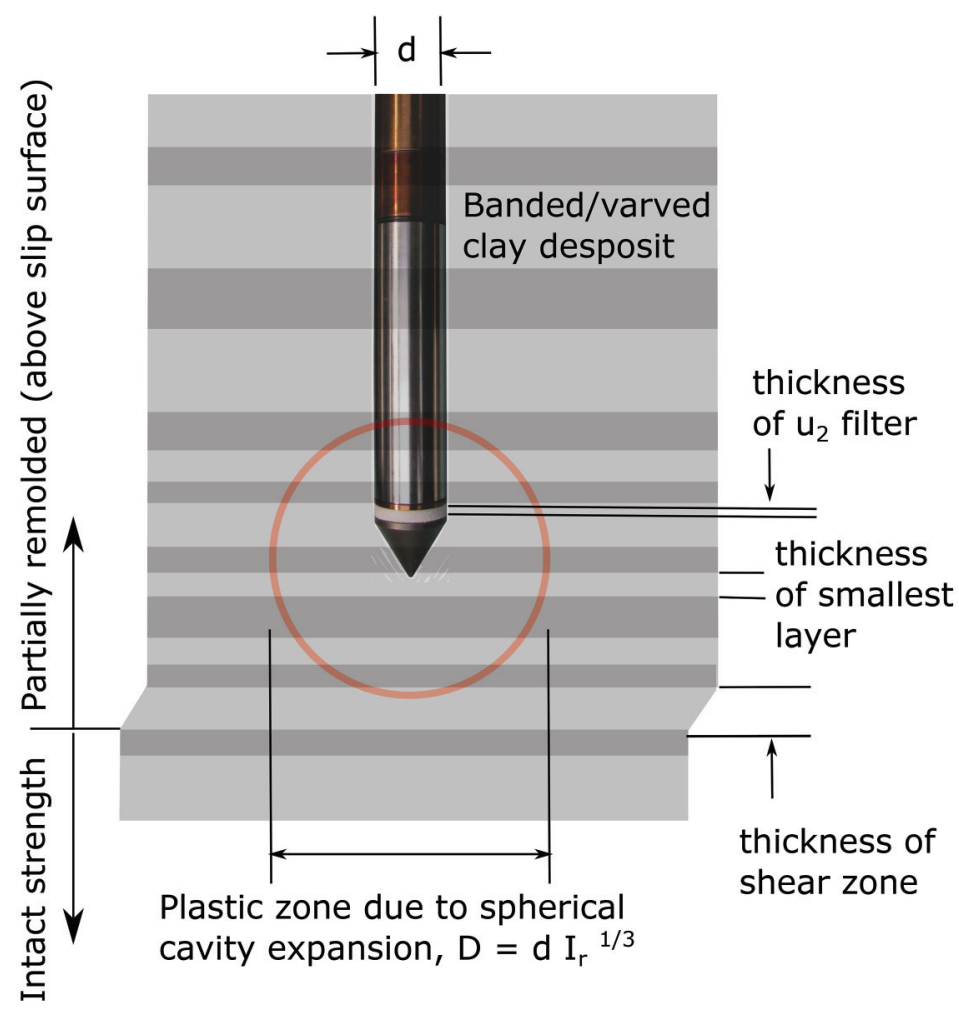

\section{b) Interpretation}

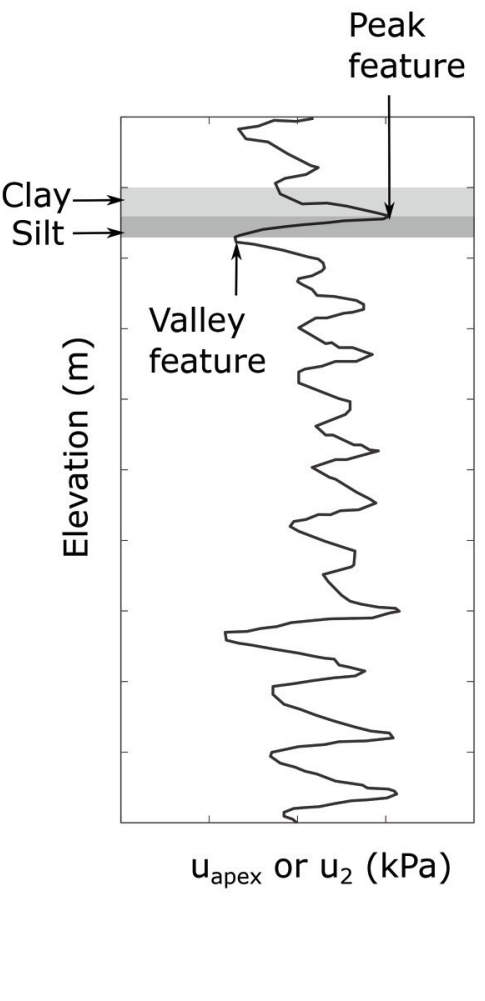

situ evidence of orientation of soil layers could extend this style of analysis to the full depth of the landslide.

The ability of measurements of cone tip resistance, pore pressure, and shaft friction to detect increasingly thin layers is limited by the length scale associated with each of these measurements defined by the cone diameter. Figure $1 a$ illustrates a cone of diameter, $d$, being pushed into a glaciomarine clay with bands or varves of differing clay and silt content illustrated with different levels of shading. In this illustration, the length of the cone sleeve is the least sensitive to thin layers as its length is typically on the order of three times the cone diameter. The measured sleeve resistance will therefore be an averaged response of the shear behavior of multiple layers. At the cone tip, theoretical analyses based on cavity expansion (e.g., Mayne 2009) indicates that the size of the influence zone during penetration is a function of the cone diameter and the rigidity index, $I_{\mathrm{r}}$, of the material defined as $G / s_{\mathrm{u}}$, where $G$ is the shear modulus (taken here to be the value at large deformation) and $s_{\mathrm{u}}$ is the undrained shear strength. Following Agaiby and Mayne (2018), a typical rigidity index for Champlain Sea Clay is 94, leading to an estimate of the influence zone of approximately 4-5 times the cone diameter. Numerical analyses conducted to investigate cone tip resistance behaviour to layered soils indicates that the measured tip resistance is influenced by the soil properties in each layer as well as layer geometry (e.g., Walker and Yu 2010; Mo et al. 2016), inspiring the need to develop inverse filtering procedures to correct cone penetration data for thin-layer and transition effects (Boulanger and DeJong 2018).

In contrast, the thickness of the filter element typically included at the shoulder of the cone, or the $u_{2}$ position, is on the order of typically 1-5 $\mathrm{mm}$. This provides a more localized measurement of soil layering as observed through the pore pressure response to differences in horizontal coefficient of consolidation, $c_{\mathrm{h}}$ between each layer. It is therefore not surprising that research conducted on high-resolution stratigraphic profiling has therefore focussed on using the pore pressure response.

The design of miniature probes that sacrifice all sensors except pore pressure measurement to minimize diameter has been a successful strategy in detecting soil layers at the millimetric scale (Torstensson 1977; Hird et al. 2003; DeJong et al. 2003, 2007). For example, DeJong et al. $(2003,2007)$ designed a $0.2 \mathrm{~cm}^{2}$ miniature piezocone (pore pressure only) for high-resolution stratigraphic profiling of layered clays. DeJong et al. (2003) performed a series of soundings with a $0.2 \mathrm{~cm}^{2}$ piezocone while alternating the piezometer filter location among the $u_{1}$ (mid-face of cone tip), $u_{2}$ (shoulder of cone), and $u_{\text {apex }}$ (apex of cone tip) locations to investigate the optimal location to measure the pore pressure response. The cone penetration soundings indicated that the wissa $u_{1}$ piezometer filter location, followed by the $u_{1}$ and $u_{2}$ filters, produced the highest sensitivity and change in pore pressure magnitude. The interpretation of the pore pressure response on penetration of a varved glaciomarine deposits inspired from the observations of DeJong et al. (2007) is presented in Fig. $1 b$. In this data, bands of clay or silt-rich marine clay can be identified by the peak and valley features in the pore pressure response. DeJong et al. (2007) report a distinct drop in pore pressure was evident at each silt layer, with clay layers causing a gradual rise in pore pressure throughout the layer of clay. The thickness of a silt to clay pair and clay to silt pair can be determined by the spacing of peak and valley features, respectively. In this work, we hypothesize that a frequency domain analysis of pore pressure data may provide additional insights into the spatial 
Fig. 2. The four different sized cones tested at Mud Creek: (a) $15 \mathrm{~cm}^{2},(b) 10 \mathrm{~cm}^{2}$, and (c) $5 \mathrm{~cm}^{2}$ all with tip resistance, sleeve friction, and $u_{2}$ shoulder pore pressure measurement sensors; and (d) $2 \mathrm{~cm}^{2} u_{2}$ pore pressure only device. [Colour online.]

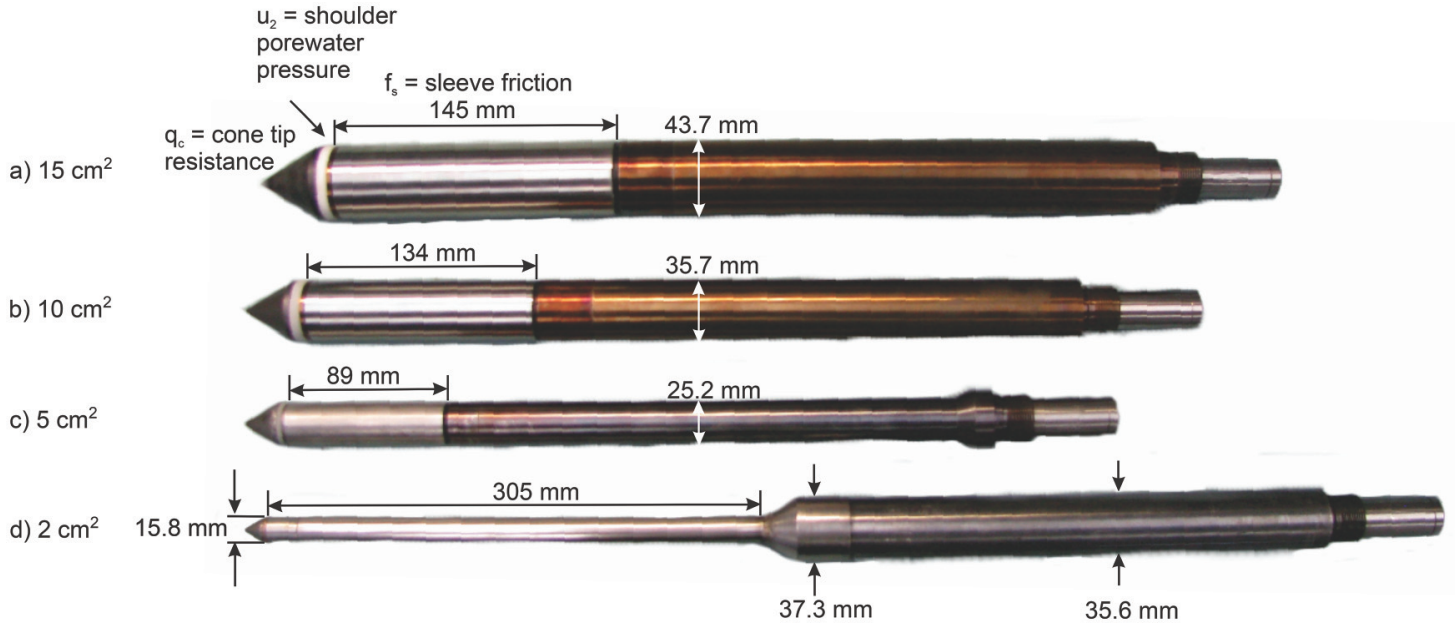

frequency of layering. Furthermore, this analysis may provide insights into the frequency content that may be lost if a cone is not fully saturated.

While miniature probes with a $u_{\text {apex }}$ piezometer filter location have been shown to be the optimal configuration for high-resolution stratigraphic profiling, the forensic use of CPT techniques for landslide back analyses also requires observations of strength. A strategy using the smallest possible cone that is of sufficient size to retain both the tip and sleeve friction measurements is a compromise position between these competing measurement outcomes. Successful use of such a strategy has been reported by Hird and Springman (2006), who used a $5 \mathrm{~cm}^{2}$ cone to successfully detect layering on the order of $2-4 \mathrm{~mm}$ in thickness. An additional compromise relates to the position of the dynamic pore pressure sensor. In strength measurement applications, the $u_{2}$ pore pressure filter location has the additional advantage that $u_{2}$ observations can be used to correct the tip resistance from dynamic pore pressures that develop at the shoulder joint during penetration. The tip resistance, $q_{\mathrm{c}}$, can be corrected for the effects of the pressures at the joints, termed the corrected total cone tip resistance, $q_{\mathrm{t}}$ :

$$
q_{\mathrm{t}}=q_{\mathrm{c}}+\left(1-a_{\text {net }}\right) u_{2}
$$

where $a_{\text {net }}$ is the net area ratio of the cone tip. The $a_{\text {net }}$ for cones used in this study was measured to be 0.8 .

Measures of the intact and remolded strength of a sensitive clay involved in a landslide can be inferred from the classical undrained bearing capacity interpretation of cone tip resistance commonly applied in clay soils:

$$
\text { (2) } \quad S_{\mathrm{u}}=\frac{\left(q_{\mathrm{t}}-\sigma_{\mathrm{v}}\right)}{N_{\mathrm{kt}}}
$$

where, in soft intact clays, the $N_{\mathrm{kt}}$ value will typically range between 10 and 20 (Lunne et al. 1997). For this investigation, undrained shear strengths will be calculated using an $N_{\mathrm{kt}}$ value of 9.94 for Champlain Sea Clay, shown by Agaiby and Mayne (2018) to be in good agreement with values of undrained strength presented, including field vane tests and laboratory CAUC and CIUC triaxial tests at the nearby Gloucester test site. The unit weight at the Mud Creek field site was found to be $15.5 \mathrm{kN} / \mathrm{m}^{3}$. Application of this relationship to cone holes penetrated through the landslide debris and neighbouring intact material (i.e., at a nearby location outside the scarp of the failure) can therefore yield evidence of the representative undrained strength of the remolded and intact material, respectively.
Slip surface detection from CPT traces can either be made from the cone tip resistance or the pore pressure response to shearing. Even if the thickness of the shear zone is small as illustrated in Fig. 1a, the elevation of the slip surface can be detected in a cone hole penetrated through the landslide debris as the elevation at which the cone tip resistance increases from a remolded value above the slip surface to the intact value immediately below the slip surface. Such a strategy for slip surface detection has been highly successfully adopted in sensitive clay landslide case studies in Maskinongé, Quebec (Demers et al.1999), and at Saint-Jude, Quebec (Locat et al. 2017). Slip surface detection can also be made using measurements of pore pressure through the destructurisation of the bands or varves as previously discussed and the lower overall magnitude of pore pressure generated during penetration. As the excess pore pressures generated around the cone are directly related to the rigidity index of the material (Teh and Houlsby 1991), the significantly lower undrained strength of the material will translate into a lower rigidity index and a lower magnitude of excess pore-water pressure generated on shearing. Additional evidence of the elevation of the slip surface can therefore come from cone holes penetrated through the landslide debris as the elevation at which these two aspects of the pore pressure response returns to the behaviour of the intact material.

While yielding exceedingly valuable information on sensitive clay landslides, concerns over triggering potential landslide retrogression restricts the use of typical workflow using a heavy tracked CPT rig on marginally stable areas such as inside an incipient failure zone (i.e., inside a scarp prone to failure) or immediately adjacent to a scarp. In such locations a low-weight handoperated CPT frame may enable novel in situ measurements of the degree of remolding currently experienced by soil subject to progressive failure. However, uncertainties remain whether such a strategy could be effective. Firstly, to minimise the weight and transportability of the manual CPT, penetration must occur under a controlled rate under hand power rather than hydraulic actuation. This restricts the magnitude of undrained strengths that may be tested. The pushing frame must also be able to provide a reaction to the forces generated during penetration. Given the low remolded strength of the soil, it is unclear whether screw anchors embedded into the surface will mobilise sufficient force to provide this reaction. Further, since one of the goals is to conduct high-resolution stratigraphic profiling, a lower penetration rate than the standard $2 \mathrm{~cm} / \mathrm{s}$ would be advantageous to simplify data acquisition rate requirements, if it could be confirmed to not affect the CPT response in sensitive clays. 
Fig. 3. CPT systems used at Mud Creek test site: (a) 20-ton tracked rig and $(b)$ portable hand-actuated CPT system. [Colour online.]
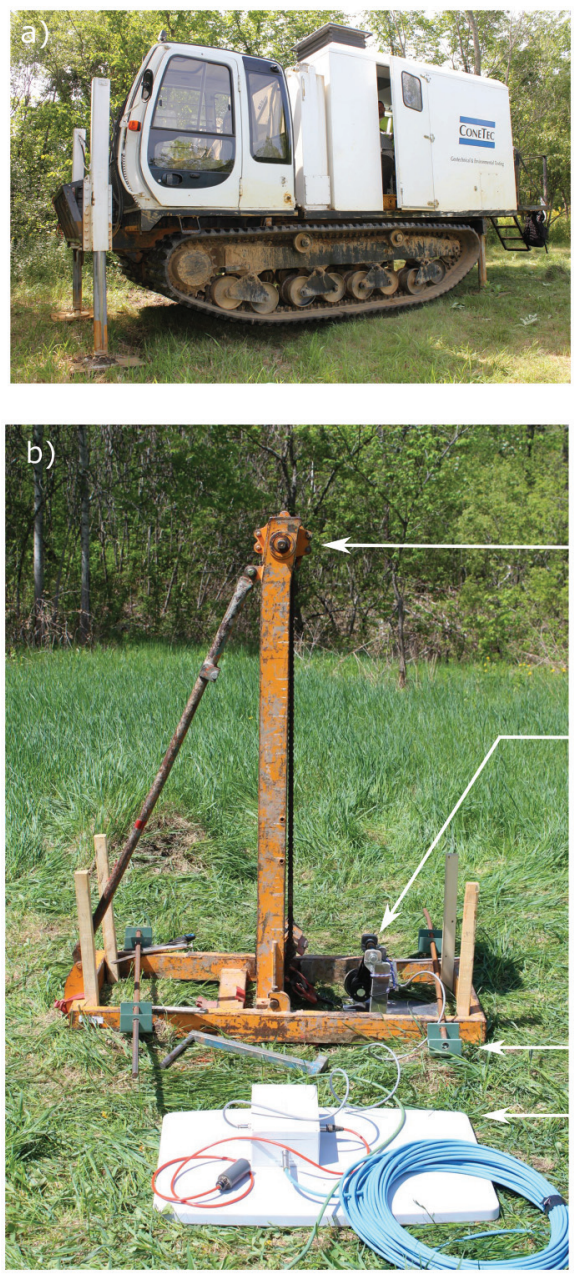

Hand acutated drive mechanism

Fig. 4. Photographs of Mud Creek landslide test site in (a) September 2009 exhibiting a $1.2 \mathrm{~m}$ high scarp visible at the crest of the $11 \mathrm{~m}$ high slope inclined at 3H:1V and (b) May 2013 during CPT testing at the slope crest after the 2012 and 2013 retrogression events. [Colour online.]

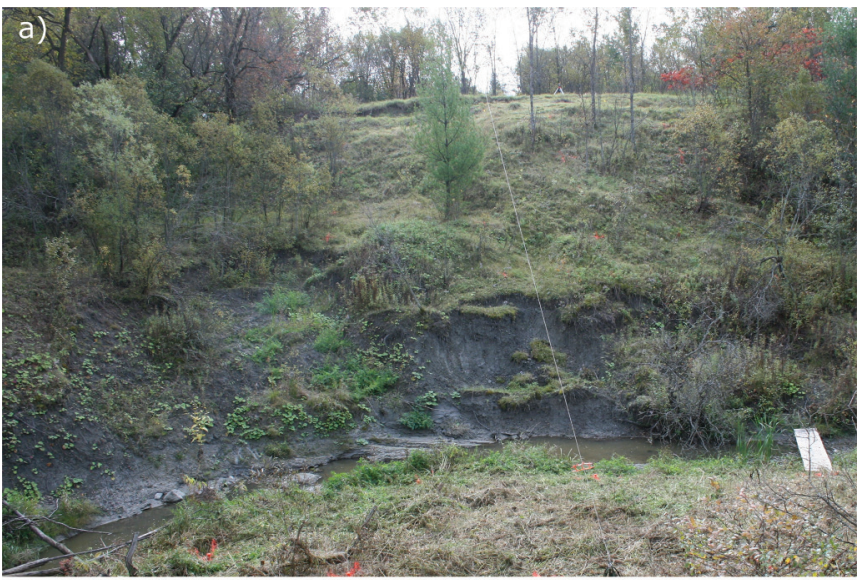

Depth encoder wheel

Reaction system (screw anchors)

Data aquistion break out box

The objective of this paper is to further advance the use of cone penetration testing for the investigation of sensitive clay landslides, specifically to (i) quantify the effect of cone size on pore pressures generated by the penetration of four different sized cones; (ii) develop a frequency domain analysis of pore pressure data to support millimetric-scale stratigraphic profiling and provide insights into the frequency content that may be lost if a cone is not fully saturated; and (iii) confirm whether a hand-operated mobile CPT could permit the quantification of the degree of remolding under progressive failure in metastable areas of a landslide where conventional tracked rigs are unable to gain access.

\section{Cone penetration testing}

Four different sized cones were selected to assess the effect of cone size on minimetric-scale stratigraphic profiling in a sensitive clay landslide. Each of these devices were designed with the standard tip angle of $60^{\circ}$ and to include the capability to measure pore-water pressure at the $u_{2}$ position (Fig. 2). All probes except the smallest size cone $\left(2 \mathrm{~cm}^{2}\right)$ were also fitted with sensors to measure the cone tip resistance, $q_{\mathrm{c}}$, and sleeve friction, $f_{\mathrm{s}}$. The largest two sizes, the 15 and $10 \mathrm{~cm}^{2}$ cones, are the typical size devices used in North American practice. A $5 \mathrm{~cm}^{2}$ cone is also included in the test matrix, as this size was observed to have excellent performance in stratigraphic profiling by Hird and Springman (2006). This size also represents the current limit on the miniaturization of thermal-compensated $q_{\mathrm{c}}, f_{\mathrm{s}}$, and $u_{2}$ sensors

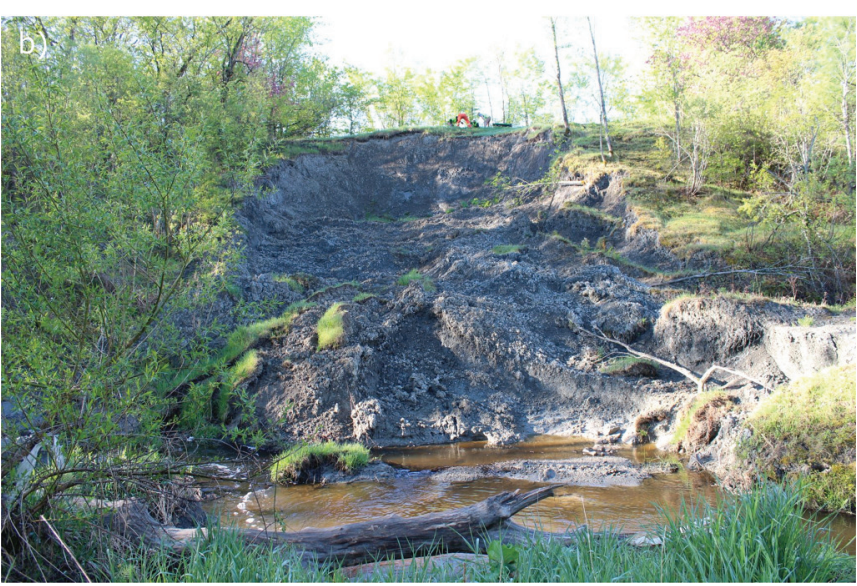

within a cone of field robustness without mechanical cross-talk between the sensor types. The need for thermal compensation will be discussed in a later section of the paper. The smallest cone $\left(2 \mathrm{~cm}^{2}\right)$ measures pore pressure at the shoulder of the cone only. As the diameter of this cone is significantly smaller than the cone rods, the distance before the tapered friction reducer must be long enough to ensure the excess pore pressures generated from soil deformation at the tapered section does not influence the $u_{2}$ measurements (e.g., Whittle et al. 2001). DeJong et al. (2007) observed an extension length equal to about two cone diameters was sufficient to avoid the effects from the tapered section. The probe length before the tapered section in Fig. $2 d$ is $305 \mathrm{~mm}$, which represents a length 19 times larger than the diameter.

Cone holes were pushed hydraulically from a 20-ton tracked rig and a hand-actuated portable CPT testing frame (Fig. 3). The portable testing frame consists of a horizontal steel base frame, a vertical chain-operated CPT guide with a geared hand-actuated drive mechanism designed for a penetration rate of $0.5 \mathrm{~cm} / \mathrm{s}$, and a steel stabilizing bar to provide bracing between these two frames. Four screw anchors were installed, one at each corner of the horizontal frame, to provide a reaction force against the forces generated during CPT penetration. The current depth of the CPT was inferred from a high-resolution depth encoder wheel that tracked the progress of penetration of the cone rods. Data from the sensors was acquired at a scanning rate of $200 \mathrm{~Hz}$, which at a penetration rate of $0.5 \mathrm{~cm} / \mathrm{s}$ corresponds to a sampling 
Fig. 5. Orthographic photograph of Mud Creek field site showing locations of initial toe failure in 2011 and outline of flow slides occurring in 2012 and 2013. The locations of CPT cone holes illustrated by marker dots for each cone size. Cone holes are numbered using the last two digits of the year of the in situ site investigation campaign followed by the hole number in that campaign. A local coordinate system is defined in the upper right-hand side of the figure along with two cross-sections that is referenced in the paper. [Colour online.]

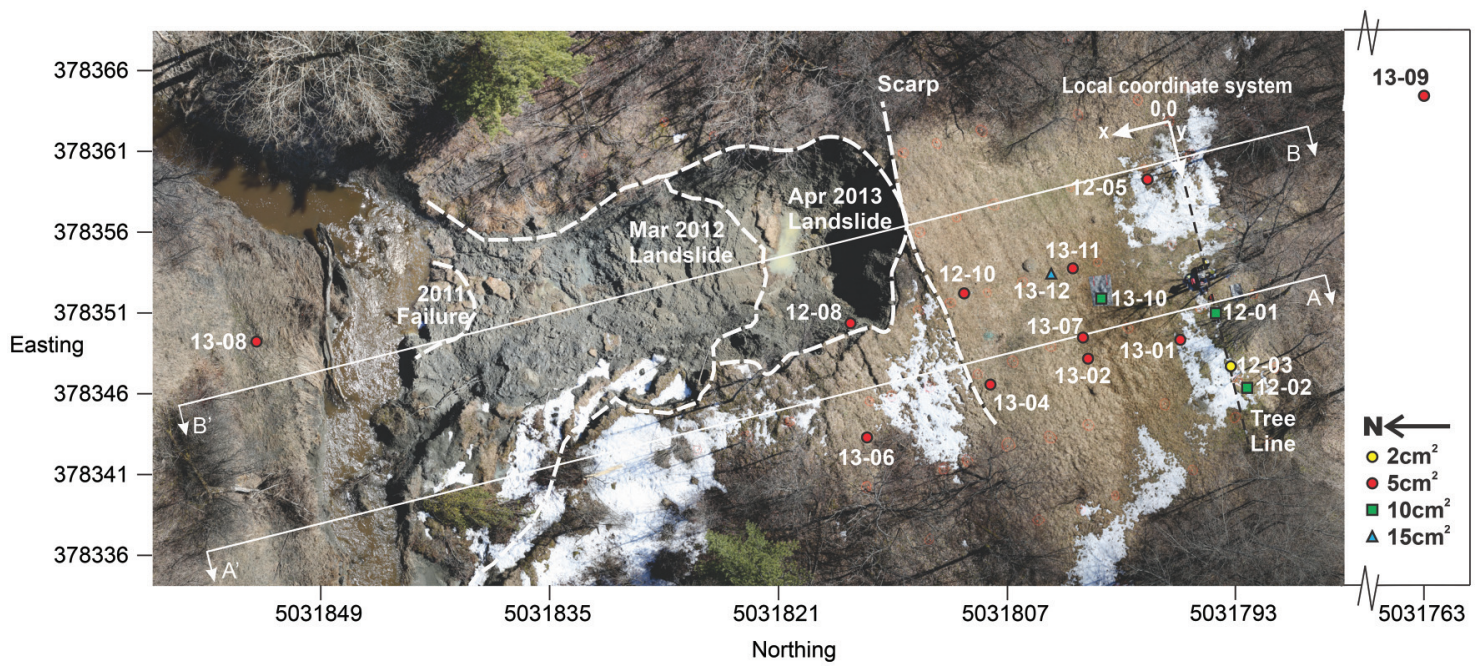

Fig. 6. Photograph of sample of lower clay unit exposed by erosion at the creek illustrating varves of alternating silt- and clay-rich layers, made visible by differential rates of drying due to evaporation of water from the sample. [Colour online.]
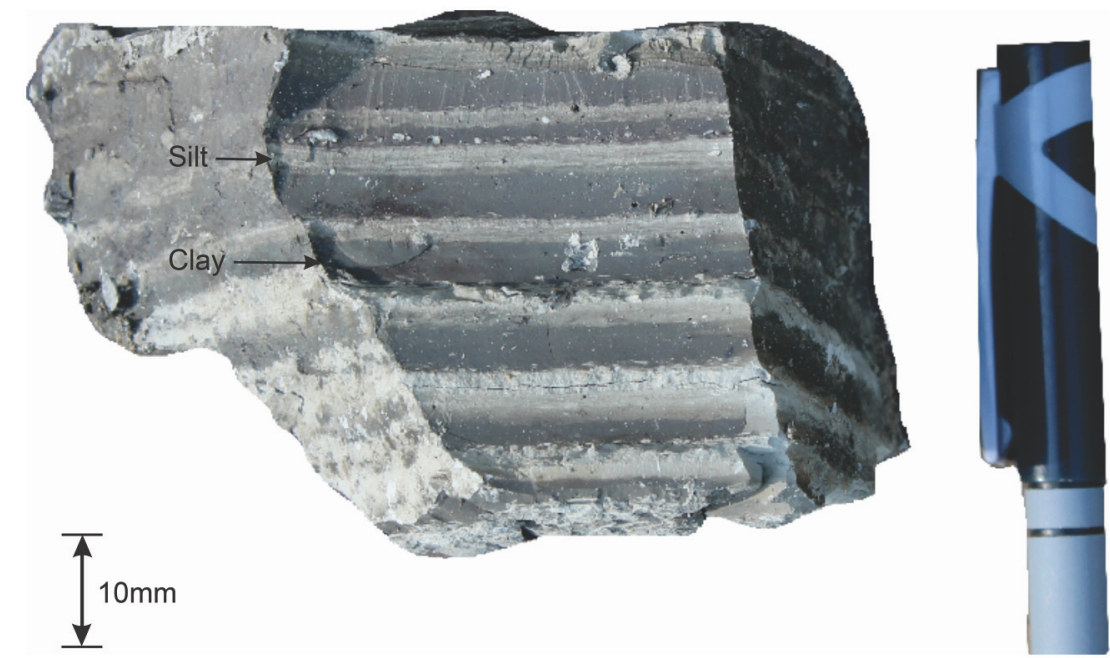

interval of $0.025 \mathrm{~mm}$. For the sake of data size reduction, the data was then processed to produce cone profiles at a spatial resolution of $1 \mathrm{~mm}$.

\section{Mud Creek landslide test site}

River bank slopes incised into Champlain Sea Clay within the urban boundary of the City of Ottawa have been observed to be highly susceptible to landslides (e.g., Sangrey and Paul 1971; Mitchell and Eden 1972; Williams et al. 1979; Hugenholtz and Lacelle 2004). In particular, the banks of Green's Creek and its tributary Mud Creek exhibit high rates of landslide occurrence, with 52 individual instances of landslide activity being identified by Hugenholtz and Lacelle (2004) over a 71-year period from 1928-1999. The Government of Canada directed the establishment of a Greenbelt for the City of Ottawa in 1958, including the protection of these watercourses, resulting in abandonment of agricultural use of lands immediately adjacent to the watercourses and gradual reforestation. The Mud Creek landslide study initiated by Queen's University in 2009 in partnership with the National Capital Commission takes advantage of the high background rate of landslide occurrence along Mud Creek to use this location as a real-world laboratory to quantify the effect of revegetation on the annual volumetric rate of landsliding using point cloud data derived from historical air photos and to conduct a long-term monitoring program using unpiloted aerial vehicle (UAV)-based photogrammetric and conventional total station surveying to assess whether surface displacement measurements can serve as an indicator of progressive failure. The present study extends this work with an in-depth investigation of CPT techniques for stratigraphic profiling, slip surface detection, and assessment of remolding in sensitive clay landslides.

A key feature of the landslides in this watershed is the unique episodic nature of retrogression experienced by the slopes. Unlike typical sensitive clay landslide events in which retrogression tends to occur within a single event (e.g., typical sensitive clay landslides in the Champlain Sea Clay such as Saint-Jude, Lemieux, etc.), 
retrogression of sensitive clay landslides along the banks of Green's and Mud creeks occur episodically, with successive failures enlarging a given landslide several years-to-decades after the initial failure (Hugenholtz and Lacelle 2004). Of particular relevance to the present study, the fact the landslide retrogresses akin to stopmotion animation provides a unique opportunity to access temporarily stable areas of the slope to quantify the degree of remolding at various times and locations within the failure process with a portable CPT system.

Photographs of the Mud Creek test site are shown in Fig. 4. At this location the creek is $11 \mathrm{~m}$ below the elevation of the table land, with the slope inclined at approximately $3 \mathrm{H}: 1 \mathrm{~V}$. At the start of monitoring in September 2009, the slope was observed to have an approximately $1.2 \mathrm{~m}$ high scarp at the crest of the slope and a small localised failure at the toe of the slope (Fig. 4a). A similar view after several years of monitoring, including the observation of two retrogressive events in the spring of 2012 and 2013 is shown in Fig. $4 b$. At the time of this photograph in May 2013, the landslide has retrogressed back to the original scarp at the crest of the slope (CPT test crew is visible at the crest of the slope for scale). An orthographic photograph of Mud Creek field site created from UAV imaging showing locations of initial toe failure in 2011 and outline of flow slides occurring in 2012 and 2013 is presented in Fig. 5. The locations of CPT cone holes are also illustrated in this figure by unique marker dots corresponding to each of the four different sized cones tested on the site. Cone holes are numbered using the last two digits of the year of the in situ site investigation campaign followed by the hole number in that campaign. A local coordinate system is defined in the upper right-hand side of the figure using an axis orientation normal to the slope along with two cross-sections that will be referenced later in the manuscript. The photograph of the slope presented in Fig. $4 b$ was taken at the location of CPT sounding 13-08, with the felled tree in the foreground being visible in both images. The CPT soundings can be divided into three categories - a cone hole in the far field away from the landslide (CPT13-09), cone holes in the tableland in the stable land above the crest scarp, and cone holes penetrated through temporarily stable soil (i.e., CPT12-08 and CPT13-06 downslope of the crest scarp denoted by the dotted line). Cone hole CPT12-08 was conducted in 2012 immediately above the scarp of the 2012 flow, a region that subsequently experienced flow failure in 2013, and therefore is absent from the 2013 orthographic image in Fig. 5.

Surface exposures of clay due to incision of the creek confirm the observations of Fransham and Gadd (1977) of an upper clay with gray bands and a lower clay with thinner varves. A photograph of a specimen of the lower clay is presented in Fig. 6 using the cap of a pen for scale, with the varves of alternating silt- and clay-rich layers are made visible by differential rates of drying due to evaporation of water from the specimen. Based on these observations, the minimum thickness of a slit or clay layer in the lower clay unit is expected to on the order of $3 \mathrm{~mm}$.

\section{CPT results}

\section{Importance of thermal compensation}

The low remolded strength of sensitive clays results in extremely low sleeve resistance and low values of tip resistance in comparison to more conventional soils. CPT of sensitive clays therefore requires particular attention to ensure thermal changes from the ambient environment at the soil surface to the subsurface are fully compensated. The importance of thermal compensation is illustrated by the thermal profiles measured using the thermistor onboard the CPT probe during the two phases of CPT testing - late summer 2012 and late spring 2013 in Fig. 7. These profiles illustrate that the cone begins penetration at the ambient air temperature of $22-25{ }^{\circ} \mathrm{C}$ (care was taken to ensure cone was not left exposed to solar radiation, as this could significantly elevate the initial temperature)
Fig. 7. Importance of thermal compensation for sensors on cone. Initially at air temperature (i.e., CPT purposefully left in the shade), the temperature measured on board the cone is a function of the thermal profile at the site, in this case resulting in over a $15{ }^{\circ} \mathrm{C}$ temperature change.

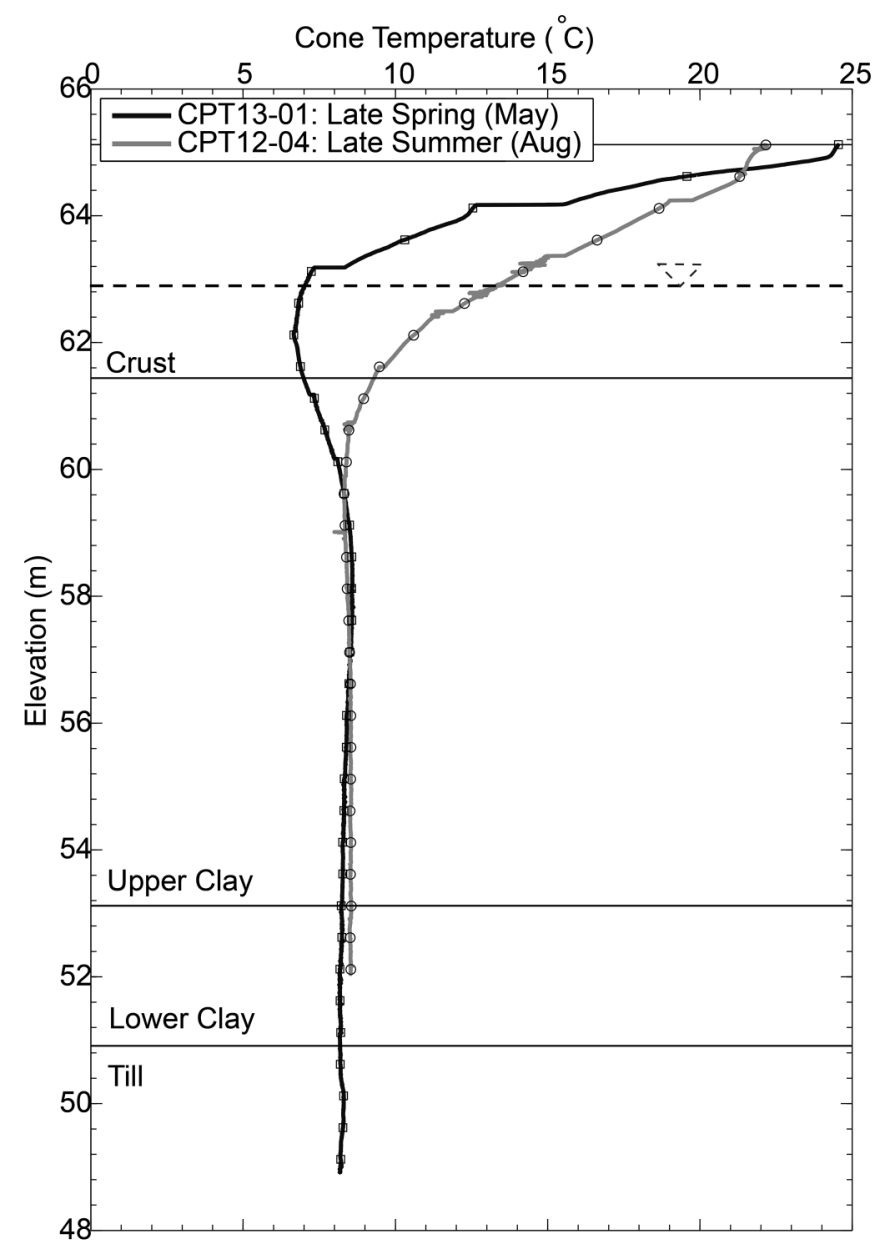

before tracking the seasonally active thermal profile of the soil until a constant value of $8.5^{\circ} \mathrm{C}$ is reached at a depth of approximately $6 \mathrm{~m}$. As the voltage output of each sensor is affected by a change in temperature during field testing, the raw data from each push must be corrected during post-processing. A temperature check was performed in the laboratory to determine the temperature shift $\left(\right.$ volts $/{ }^{\circ} \mathrm{C}$ ) of each probe transducer for post processing correction.

\section{Effect of penetration rate and cone size}

Although the stratigraphy of the site will be discussed in detail later, a brief description is described at this stage of the manuscript to provide a general orientation to the site. The results of Fig. 8 indicate that the stratigraphy of the landslide can be divided into four main units: three layers of Champlain Sea Clay consisting of a surficial crust (Unit A), a banded upper clay (Unit B), a varved lower clay (Unit C), and a till deposit (Unit D) in which the cone reaches refusal.

As the hand-actuated drive mechanism of the portable CPT testing frame is designed for a penetration rate of $0.5 \mathrm{~cm} / \mathrm{s}$ rather than the standard penetration rate of $2 \mathrm{~cm} / \mathrm{s}$, the first cone holes conducted on site were to assess the effect of the reduced penetration rate on the tip resistance, sleeve friction, and pore pressure generated by the penetration of a $10 \mathrm{~cm}^{2}$ cone. The results of 
Fig. 8. Stratigraphic profile and effect of penetration rate on cone tip resistance, sleeve friction, and pore pressure observed for test CPT12-1 $(2 \mathrm{~cm} / \mathrm{s})$ and test CPT12-02 $(0.5 \mathrm{~cm} / \mathrm{s})$ conducted with a $10 \mathrm{~cm}^{2}$ cone. [Colour online.]

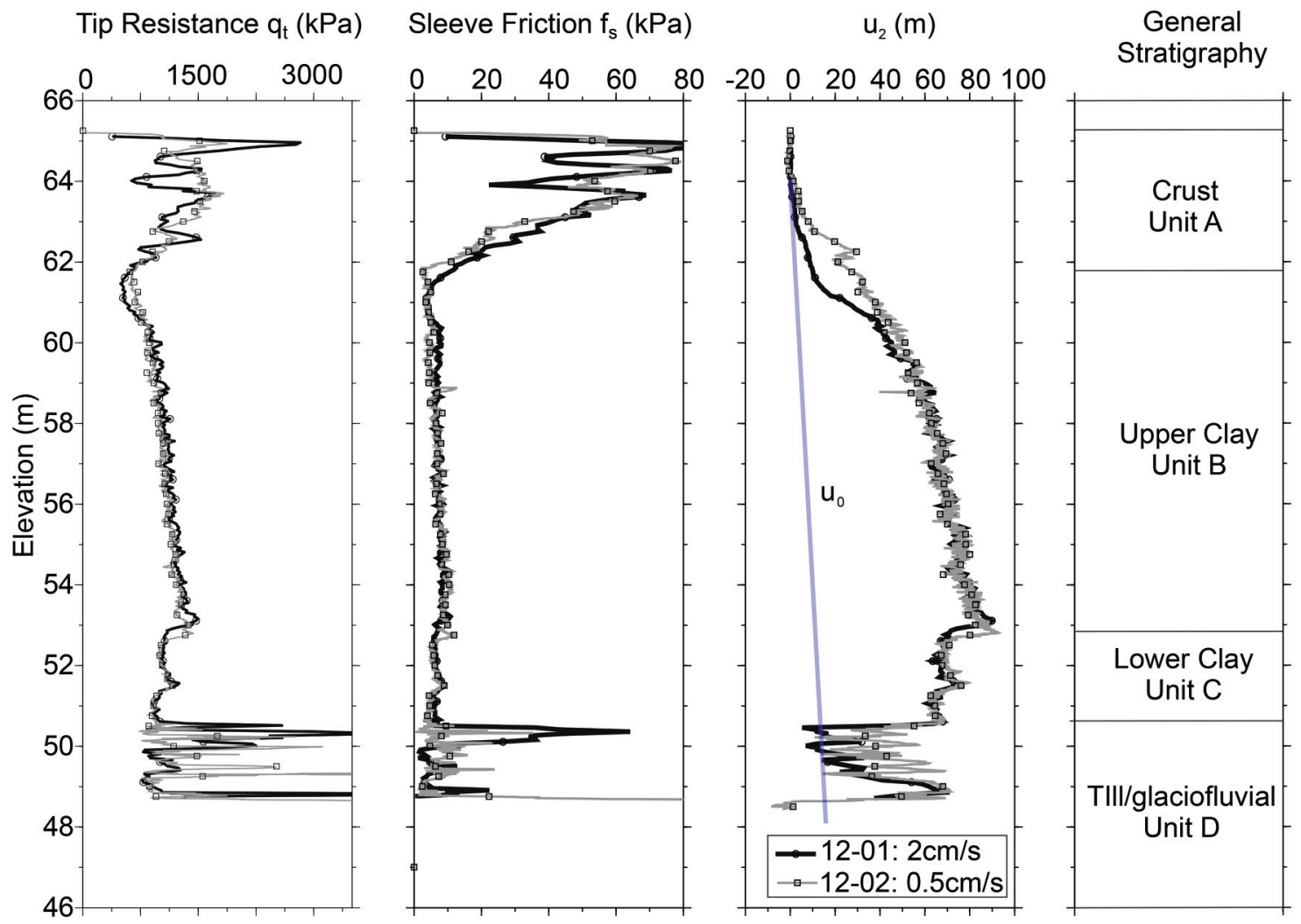

these two CPT tests are presented in Fig. 8 and indicate no discernable difference between measurements made at these two penetration rates for a $35.7 \mathrm{~mm}$ diameter cone. However, rate effects in penetration tests have been shown to be a function of both the penetration rate and the penetration diameter and are explored in the literature making use of a normalized penetration velocity (i.e., DeJong and Randolph 2012), defined as

$$
\text { (3) } \quad V=\frac{v d}{c_{\mathrm{h}}}
$$

where $v$ is cone penetration rate (conventionally $=20 \mathrm{~mm} / \mathrm{s}$ ); $d$ is penetrometer diameter (generally $35.7 \mathrm{~mm}$ ); and $c_{\mathrm{h}}$ is coefficient of consolidation (found to be $0.22 \mathrm{~mm}^{2} / \mathrm{s}$ in dissipation tests conducted in this clay unit). Therefore, at the conventional rate of penetration of $2 \mathrm{~cm} / \mathrm{s}$, the normalized penetration velocity ranges from 1450-4000 for the range of penetrometer diameters used in this study (i.e., $15.8-43.7 \mathrm{~mm}$ ). At the reduced rate of penetration of $5 \mathrm{~mm} / \mathrm{s}$, the normalized penetration velocities drop to 3601000; however, remain about the normalized velocities considered to be required for fully undrained penetration (e.g., 30-100).

Cone penetration testing was performed with the $2,5,10$, and $15 \mathrm{~cm}^{2}$ cones to evaluate the effects of the varying cone area on the measured parameters: cone tip resistance, $q_{\mathrm{c}}$, sleeve friction, $f_{\mathrm{s}}$ and pore-water pressure measured at the $u_{2}$ position. The data from these four soundings are presented in Fig. 9.

The corrected total tip resistance measured by the three different sized cones containing the tip stress sensor show excellent visual agreement in the upper clay and lower clay units, with no trend based on cone size observed in the variability between cone holes. In contrast, the tip resistance in the crust unit shows considerable variation. Given that no trend exists with cone size, it is hypothesised that this variation is due to the inherent variability of the crust layer and surficial effects such as the variable distance of each cone hole to large trees, etc. (i.e., as illustrated in Fig. 5, cone holes 13-03 and 12-02, were conducted near the tree line, hole 13-12 was pushed $8 \mathrm{~m}$ away further away from the tree line, and hole 13-09 was conducted in grassland in the far field).

Similarly to the trends observed for tip resistance, the three different sized cones produced observations of sleeve friction with excellent visual agreement in the upper clay and lower clay units. As sleeve friction is typically quite low in Champlain Sea Clay $(10 \mathrm{kPa})$, errors in the datum prior to testing and pressures at the cone joints during penetration should be expected to influence the sleeve friction sounding (Hird and Springman 2006). The degree of agreement observed in Fig. 9 illustrates that the care exercised to not overtighten the cone tip - porous filter interface and induce an initial apparent sleeve friction was successful.

In contrast, measurements of pore pressure generated at the $u_{2}$ position were observed to vary considerably with cone size, with the magnitude of pore pressure response decreasing with cone size from $15,10,5$, to the $2 \mathrm{~cm}^{2}$ cone. Teh and Houlsby (1991) developed a normalised time factor, $T^{*}$, to account for the size of the cone and the properties of the soil:

(4) $\quad T^{*}=\frac{c_{\mathrm{h}} t}{a^{2} \sqrt{I_{\mathrm{r}}}}$

where $t$ is the time of dissipation, $c_{\mathrm{h}}$ is the coefficient of consolidation, $a$ is the cone radius, and $I_{\mathrm{r}}$ is the rigidity index. As expected from this relationship, the smallest diameter cone was observed to have the fastest dissipation rate, exemplified in Fig. 9, by the marked dissipation of the $u_{2}$ pore pressure of the $2 \mathrm{~cm}^{2}$ cone during every short rod break (i.e., location where an additional rod was added for the next push). 
Fig. 9. Effect of cone size on tip resistance, sleeve friction, and pore pressure measured at the $u_{2}$ position. [Colour online.]
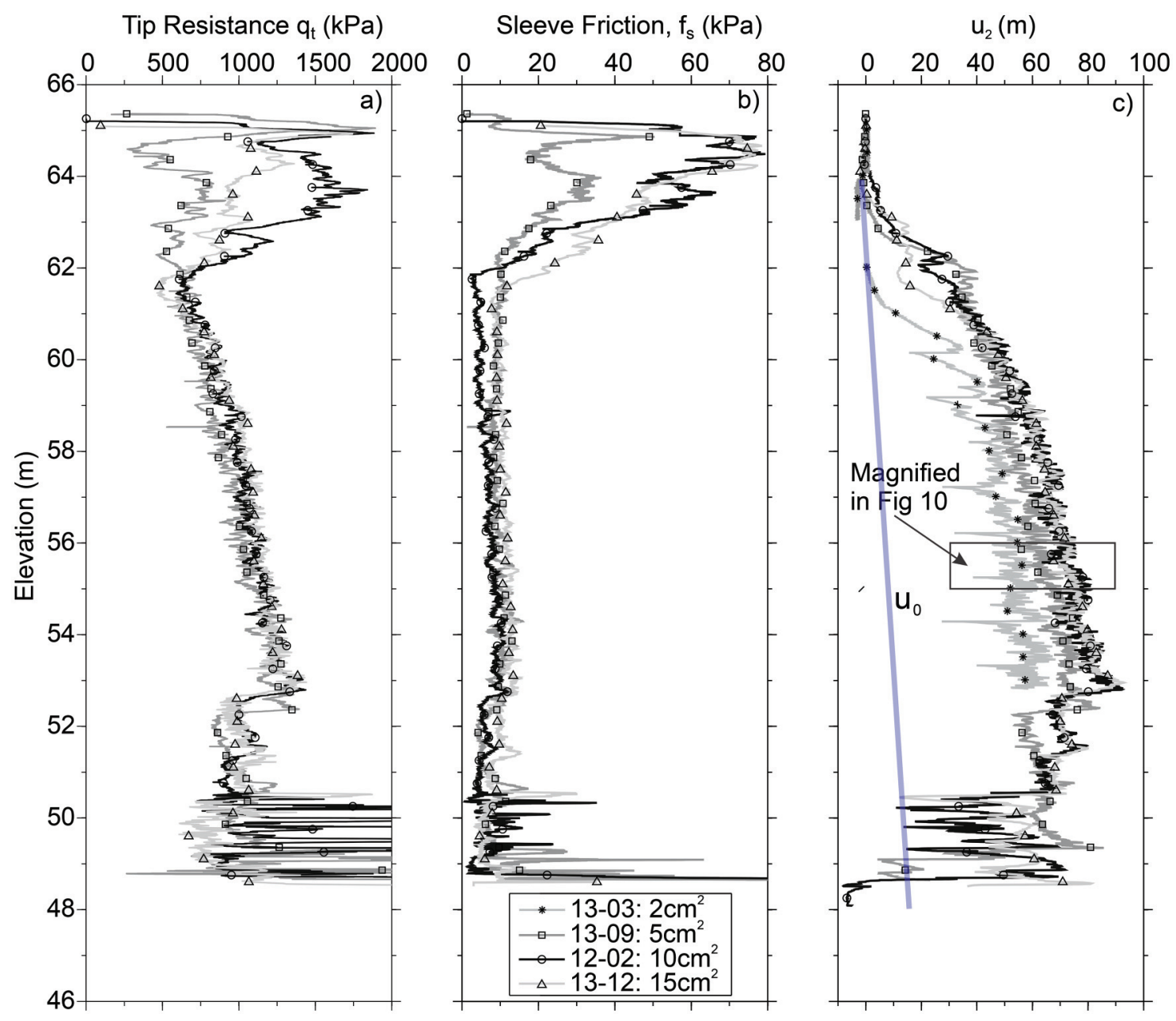

The magnitude of $u_{2}$ pore pressure generated with over a $1 \mathrm{~m}$ length of push (i.e., from elevations 56 to $55 \mathrm{~m}$ highlighted in Fig. 9) are shown at an enlarged scale in Fig. 10a. This enlarged view indicates that the magnitude of pore pressure generated tends to increase with cone diameter. This phenomenon is explored in more detail in Fig. 10b, in which the mean pore pressure generated over this $1 \mathrm{~m}$ length of push for each cone size is plotted against cone diameter. These observations show that the magnitude of pore pressure generated at the $u_{2}$ position was observed to increase nonlinearly with cone size. This finding suggests that further research using large deformation numerical modelling is warranted to explore size effects on pore pressures generated during cone testing of structured materials and in particular to investigate the potential influence of this phenomenon on the undrained strength calculated from direct correlations to excess pore-water pressure measurements.

\section{Effect of partial saturation}

The success of CPT techniques for stratigraphic profiling thin layers is highly dependent on the ability of the filter element of the cone's pore pressure measurement system to remain saturated during penetration (DeJong et al. 2007). Typical saturation fluids used in practice include glycerin and silicon oil, as they are more resistant to desaturation under the action of evaporation or during penetration in unsaturated soils due to their higher viscosity than water. In this study, a rigorous saturation process for the pore pressure measurement system was adopted, including ensuring each of the porous polymer filters were saturated under a full vacuum and submerged in the pore fluid until testing. Prior to installation of the filter, a hypodermic needle used to fill and flush any potential bubbles out of the sensor reservoir. During final assembly of the cone, compression of the pore fluid during installation of the tip served to flushed excess fluid out of the reservoir, completing a fully saturated hydraulic connection between the transducer diaphragm and the porous filter. Glycerin was used to saturate the 5,10 , and $15 \mathrm{~cm}^{2}$ cones, whereas silicon oil was required to saturate the $2 \mathrm{~cm}^{2}$ miniature piezocone to counteract its higher susceptibility to desaturation.

Past work by Rad and Tumay (1985) have indicated that insufficient saturation of the CPT filter element can result in lag time in the measured pore pressure response. The importance of $u_{2}$ filter saturation on the outcomes of stratigraphic profiling in this study was investigated by conducting two $5 \mathrm{~cm}^{2}$ cone holes in close proximity: one with a rigorously saturated $u_{2}$ filter element and a second with a purposefully less rigorous saturation process for the filter element to serve a point of comparison (i.e., without using a hypodermic needle to flush the reservoir, allowing the cone to remain in air instead of being submerged in pore fluid until immediately before penetration, etc.). The results of these two cone tests are presented in Fig. 11.

The pore pressure response of the saturated and poorly saturated cones illustrates that the overall magnitude of the pore-water pressure is broadly similar with depth, but with two significant differences in the poorly saturated cone profile: a time/elevation 
Fig. 10. Effect of cone size on pore pressure measured at the $u_{2}$ position: (a) detailed view of pore pressure trace between elevations 56 and $55 \mathrm{~m}$ and $(b)$ averaged $u_{2}$ value over this $1 \mathrm{~m}$ interval as a function of cone diameter.

a)

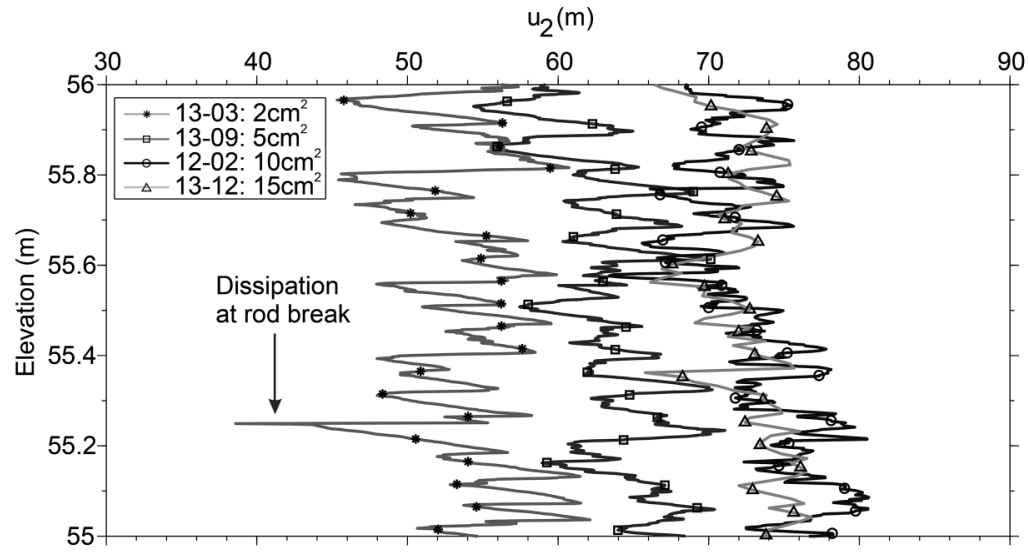

b)

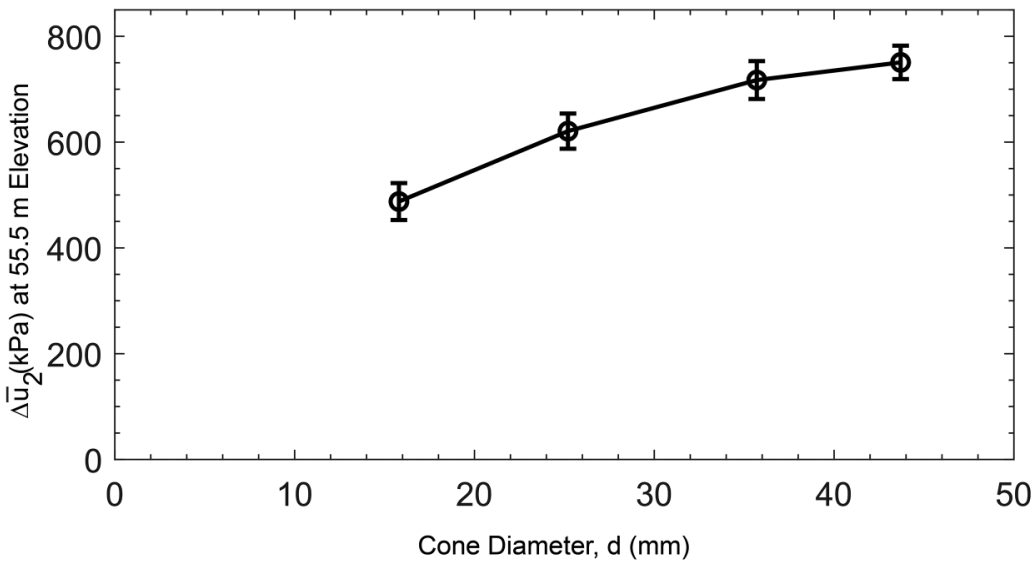

lag before pore pressures is generated and a loss of high-frequency content. Whereas the saturated cone encounters the water table at a depth of approximately $3 \mathrm{~m}$ and begins to record the $u_{2}$ response to the banded sensitive clay, the $u_{2}$ response of the poorly saturated cone requires a penetration depth of $5.5 \mathrm{~m}$ before beginning to generate the full magnitude of pore-water pressure. Therefore, the partially saturated cone was unable to identify the sequences of bands near the surficial crust. As the penetrometer was pushed below the water table into the saturated deposit, the surrounding pore water increased the saturation of the penetrometer in which the magnitude (i.e., low-frequency content of $u_{2}$ response) was correctly measured. However, the results reveal that the partially saturated penetrometer still does not have the same response as the saturated probe and was inadequate in defining the layers (i.e., high-frequency content of $u_{2}$ response).

Two $1 \mathrm{~m}$ depth sections along the observed dynamic pore pressure profiles in Fig. 11 were selected to investigate the signal content (i.e., spatial frequency of the $u_{2}$ response describing the transition between layers) using a fast Fourier transform (FFT) in the upper clay and lower clay. The alternating bands and varves are a high-frequency response of the $u_{2}$ measurements from the penetrating cone. Thus, to only highlight the layering in the clay, the low-frequency content needs to be removed from the $u_{2}$ profile. A linear fit over the $1 \mathrm{~m}$ window of data shown in Figs. 12a and $13 a$ was used as a simple means to detrend the data. Upon subtracting this low-frequency content, the detrended $u_{2}$ data was then used to calculate the spatial frequency of the layering observed by the saturated and unsaturated cones. The FFT analysis of the detrended $u_{2}$ pore pressure data from the upper clay
(Fig. 12c) indicates that the saturated cone identifies significant layer content occurring at a spatial frequency of spatial frequency of 9.8 per metre (i.e., peaks occur every $102 \mathrm{~mm}$, or every $1000 / 9.8 \mathrm{~m}=102 \mathrm{~mm}$ ) and 15.6 per metre. In contrast, the time lag associated with the poorly saturated $u_{2}$ acts in a similar way to a low-pass filter, eliminating frequency content due to layers spaced at a spatial frequency greater than 8 per metre. A poorly saturated filter, therefore, can eliminate the possibility to accurately assess layering in sensitive clay materials and, in particular, to assess whether layering has been damaged due to remolding. Similar results to that observed in the upper clay are presented in Fig. 13 for the lower clay to illustrate that the additional time of penetration under high-magnitude pore pressures has not improved the frequency response of the poorly saturated $u_{2}$ sensor.

\section{Insights into landslide mechanism}

\section{Stratigraphy and failure mechanism}

CPT tests were performed to create a stratigraphic profile of the landslide from the far field $(50 \mathrm{~m}$ back from the crest scarp in the table land) to four closely spaced cone holes spanning the distance immediately behind the crest scarp, at the crest scarp, and in front of the crest scarp in the temporarily stable portion of the landslide. The results of these $5 \mathrm{~cm}^{2}$ CPTu soundings are presented in terms of corrected total tip resistance in Fig. 14 and the $u_{2}$ response in Fig. 15. These results are plotted with their vertical axis corresponding to the position in the slope cross-section in April 2013, with the solid line representing the A-A' cross-section and the dotted line representing the $\mathrm{B}^{-\mathrm{B}^{\prime}}$ cross-section defined in Fig. 5. 
Fig. 11. Illustration of the effect of poor saturation of the $u_{2}$ sensor on the magnitude and frequency content of CPTu readings in a banded sensitive clay. Inset boxes show locations of $1 \mathrm{~m}$ comparisons of sensor behaviour in upper and lower clay units in Figs. 12 and 13 , respectively.

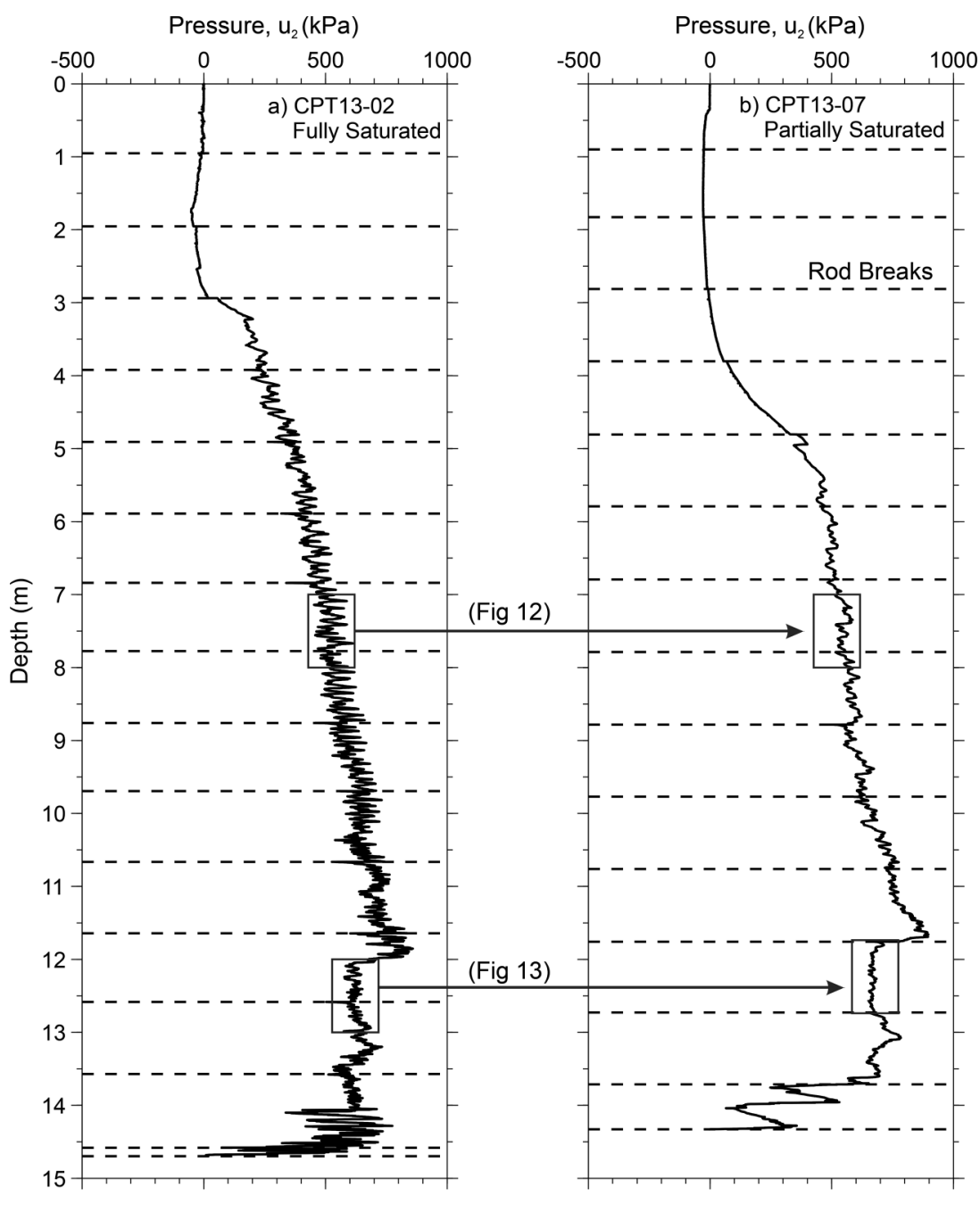

The CPT-corrected total tip resistance indicates that Unit A, the surficial crust of Champlain Sea Clay, extends approximately $3 \mathrm{~m}$ below the ground surface (mbgs) across the field site, with a displacement evident in the region inside the crest scarp. For the sake of simplified interpretation, the assumption of horizontal layers remaining horizontal has been adopted. The crust overlies $11.5 \mathrm{~m}$ of Champlain Sea Clay that is mainly classified as silt to sensitive fine grained according to the soil behavior type (SBT) charts by Robertson (1990). This layer can be further subdivided into two separate units, the upper banded clay (unit B) and the lower varved clay (Unit C), based on a distinct step changes in $q_{\mathrm{t}}$ and $u_{2}$ measurements.

The upper clay (Unit B) exhibits banding in the pore pressure profile response and comprises the upper $9 \mathrm{~m}$ of the Champlain Sea Clay profile. This layer has increasing undrained shear strength with depth, with an undrained shear strength of the intact material measured in the far field (CРT13-09) of $45 \mathrm{kPa}$ at $2.5 \mathrm{mbgs}$ increasing to $110 \mathrm{kPa}$ at $12 \mathrm{mbgs}$. The lower clay deposit (Unit C) comprised the lower $2.2 \mathrm{~m}$ of the Champlain Sea Clay deposit and was composed of sensitive fines according to the SBT charts (Robertson 1990). The lower clay has a slight inclination of $2 \%$ to $2.5 \%$ away from the toe of the slope. The distinct transition was evident in the drop of the peak undrained shear strength to from 110 to $69 \mathrm{kPa}$ as the cone penetrates the varved unit at CPT13-09.
Highly significant to the behaviour of the landslide, the lower clay represents a near-horizontal layer of lower strength. It is to be expected that the failure mechanism will likely exhibit preferential sliding in the lower clay. It is important to note that the origin of this weaker layer is from a change in Champlain Sea Clay composition due to changes in the environment of deposition (Fransham and Gadd 1977). The presence of varved clay located near the base of Champlain Sea Clay above the till deposit was first reported by Johnson (1917) and later by Antevs (1925) and Gadd (1962). Fransham and Gadd (1977) suggested the thin varved layers are an indication that glacial ice influenced deposition. The distinct change in material properties from the upper to lower clay was noticed in all CPT soundings, including CPT13-09 located $90 \mathrm{~m}$ from the toe of the slope.

Underlying the Champlain Sea Clay deposit was the till deposit (Unit D), which has no association with the Champlain Sea Clay transgression (Fransham and Gadd 1977). The till deposit was $1.5 \mathrm{~m}$ below the base of the valley and inclined at $2 \%$ to $2.5 \%$ south of the creek. The highly variable corrected tip resistance suggests that this unit was poorly sorted and may have abrupt changes in grain size altering the resistance of the penetrating cone. Therefore, the depth of refusal was quite variable, as penetration was depended on the location of the larger particles within the till. 
Fig. 12. Frequency domain analysis of $u_{2}$ measurements over typical $1 \mathrm{~m}$ push in upper clay for $(a-c)$ saturated $u_{2}$ CPTu sensor and $(d-f)$ poorly saturated $u_{2}$ CPTu sensor. Poor saturation behaves as a low-pass filter removing higher spatial frequency variations due to banding.
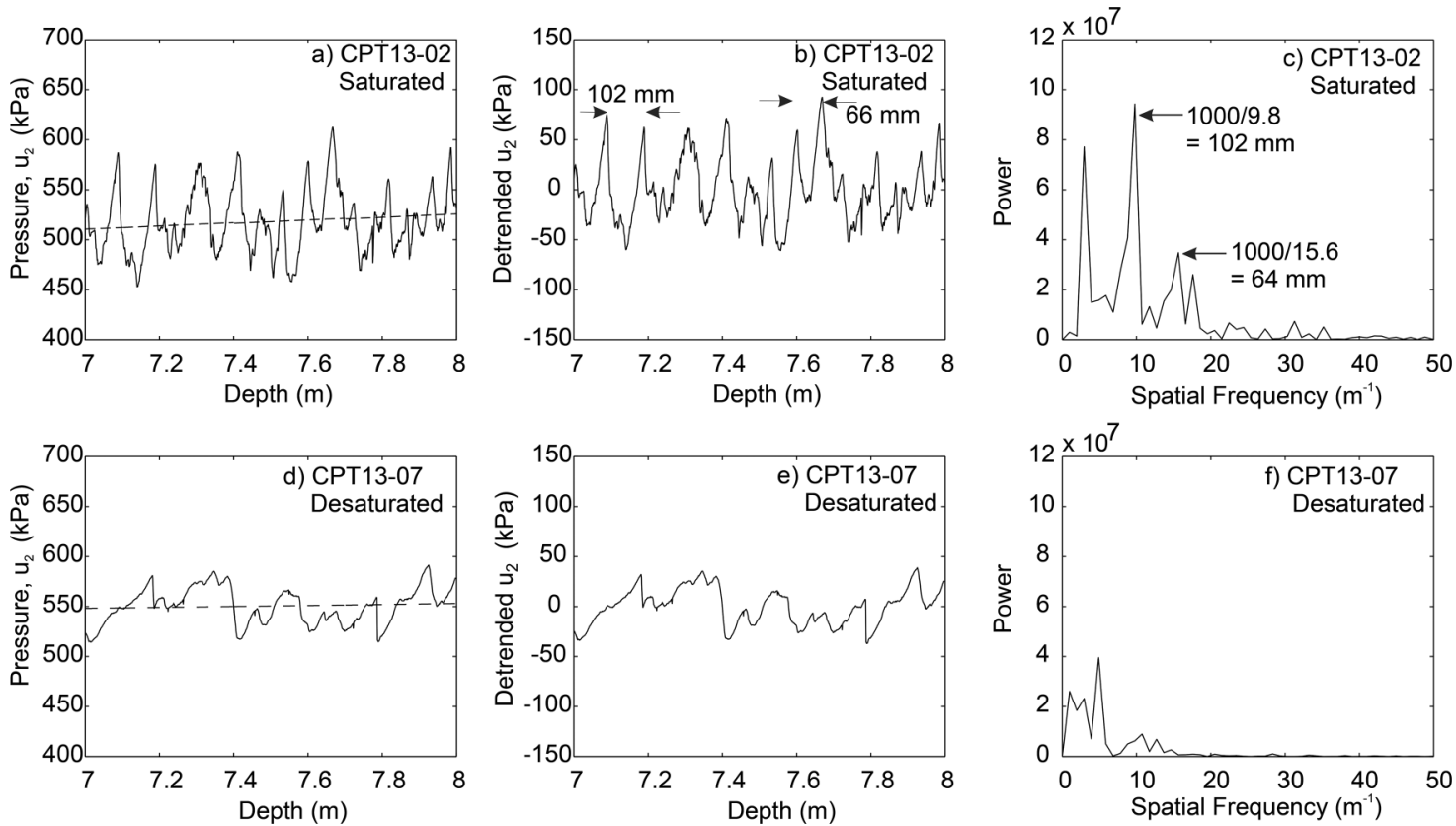

Fig. 13. Frequency domain analysis of $u_{2}$ measurements over typical $1 \mathrm{~m}$ push in lower clay for $(a-c)$ saturated $u_{2}$ CPTu sensor and $(d-f)$ poorly saturated $u_{2}$ CPTu sensor. Despite higher pressures, the poorly saturated sensor continues to act as a low-pass filter.
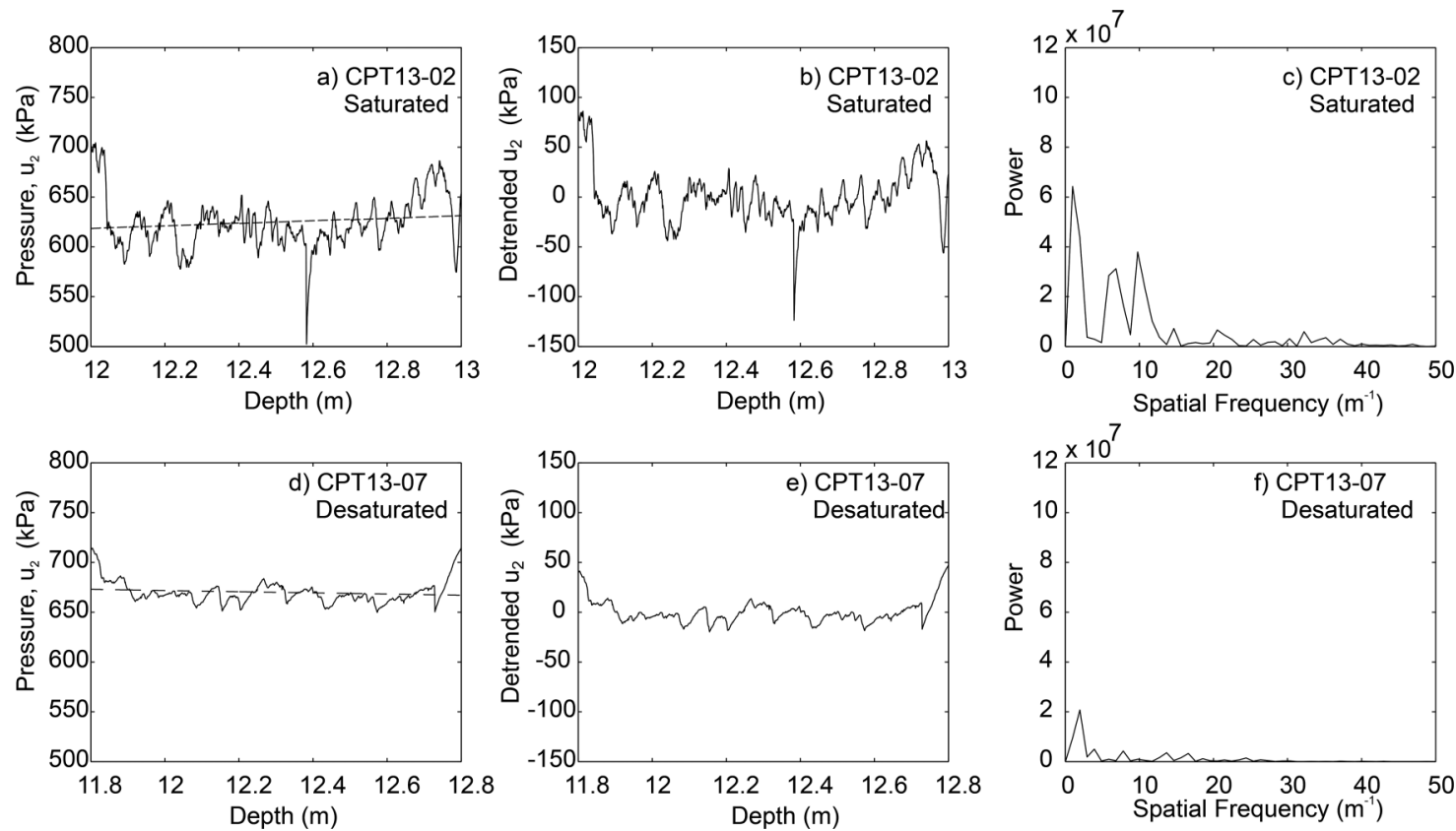

\section{Slip surface detection and degree of remolding}

CPT soundings at the site were conducted in the far field away from the landslide (CPT13-09), in the tableland in the stable land above the crest scarp, and cone holes penetrated through temporarily stable soil (i.e., CPT12-08 and CPT13-06) downslope of the crest scarp. The use of the portable CPT frame to perform investigations through temporarily stable portions of the landslide mass represents a unique opportunity to identify slip surface locations and the current degree of remolding during various stages of retrogression. Cone hole CPT12-08 was conducted in 2012 immediately above the scarp of the 2012 flow, a region that subsequently experienced flow failure in 2013 and therefore is absent from the 2013 orthographic image in Fig. 5. Test CPT13-06 was conducted 1 month after the 2013 landslide and was located to have the same approximate distance in the downslope direction (i.e., local $x$ coordinate) from the crest scarp to test whether 
Fig. 14. Cone penetration soundings of corrected tip resistance defining stratigraphic units and inferred location of failure surface from cone hole CPT13-06. Cross-sections $\mathrm{A}-\mathrm{A}^{\prime}$ and $\mathrm{B}-\mathrm{B}^{\prime}$ are defined in Fig. 3.

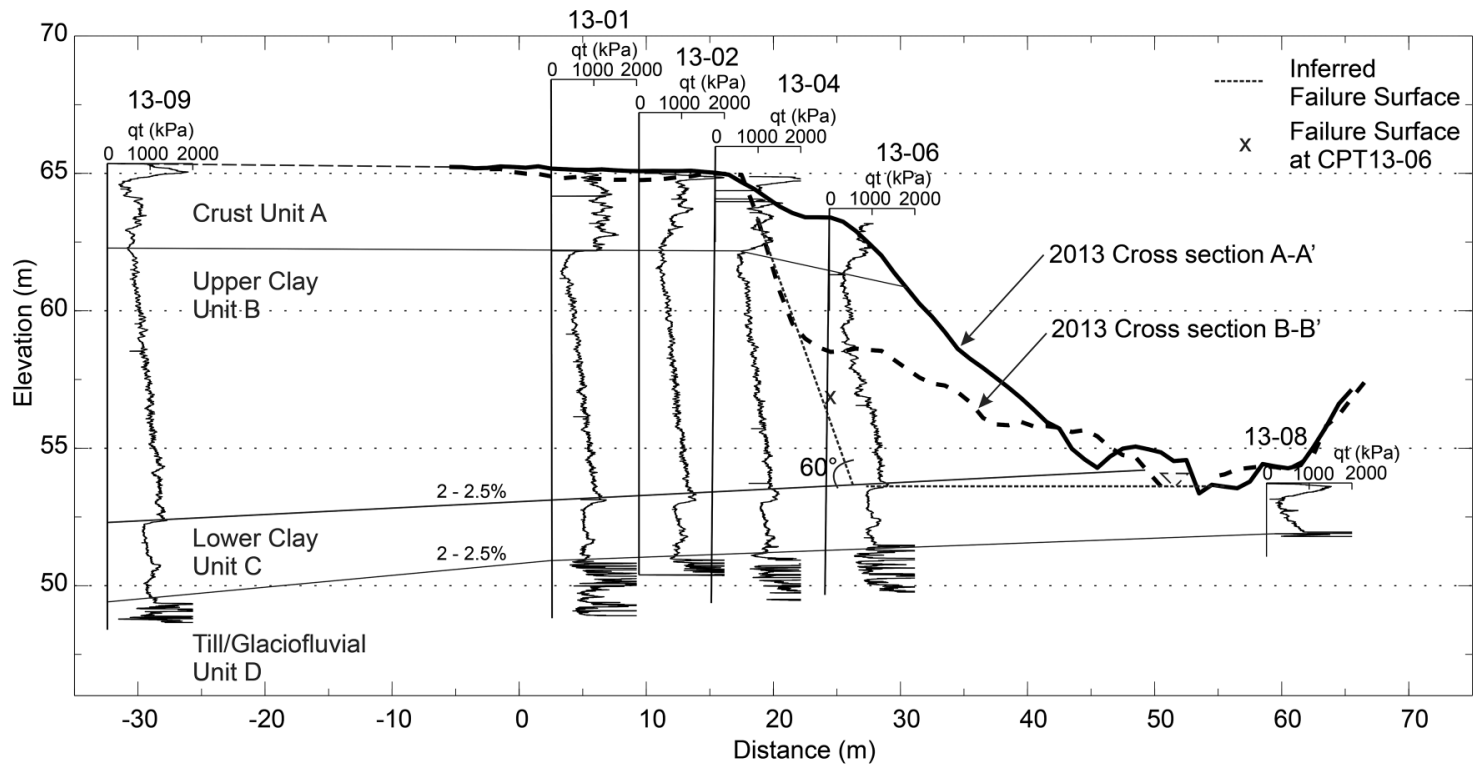

Fig. 15. Cone penetration soundings of $u_{2}$ pore pressure defining stratigraphic units and inferred location of failure surface from cone hole CPT13-06 (note loss of $u_{2}$ high-frequency response to banded clay in remolded soil above failure surface).

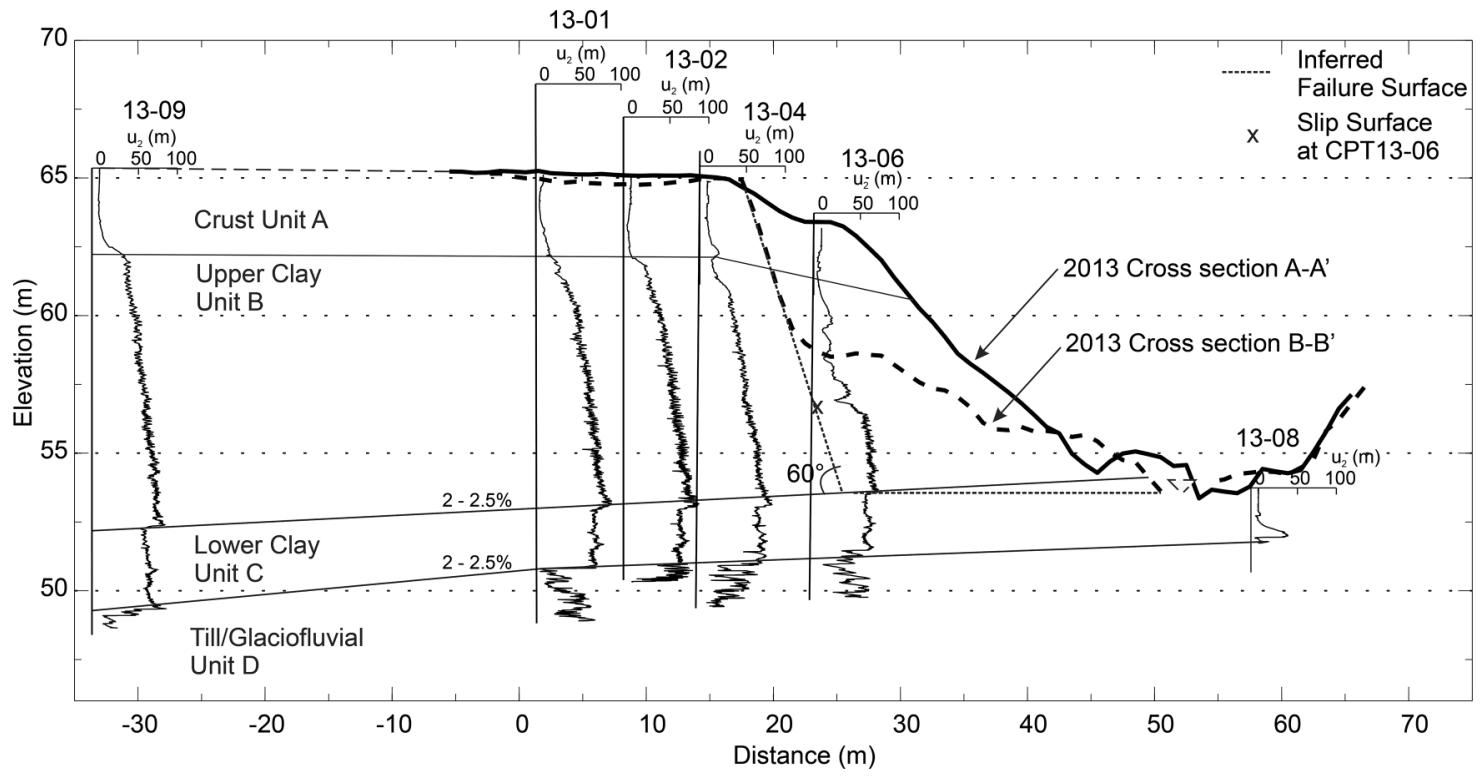

the slip surface plane in the soil that eventually evolves to be within the flow failure corresponds to the same plane under the temporarily stable flank of the slope, in other words, to test whether the slip surface at these two locations is a single plane at the same dip with a strike corresponding to the crest scarp.

The cone response through temporarily stable soil at location CPT12-08 is presented in comparison to stable location CPT12-05 in Fig. 16. The first means of comparison is the undrained strength, calculated in Fig. 16 using an $N_{\mathrm{kt}}$ of 9.96. This result clearly illustrates that the soil within the scarp have experienced significant softening, resulting in a lower undrained strength. While the discrete slip surface cannot be detected as a layer of visibly lower shear strength, the location of the slip surface can be inferred as the point of transition between the remolded soil above the slip surface and the intact soil below the slip surface at an elevation of
$56.8 \mathrm{~m}$. The second point of comparison relates to the dynamic pore pressure measured during penetration, $u_{2}$. The cone pushed in the temporarily stable remolded soil within the scarp generates significantly less pore-water pressure than through intact material. Furthermore, the high spatial frequency content of the $u_{2}$ measurements in the remolded soil is significantly diminished, providing further evidence of loss of structure. Again, the location of the slip surface can be inferred as the point of transition between the behavior of the remolded soil above the slip surface and the intact soil below. Applying this criteria to the trace of $u_{2}$ measurements in Fig. 16b, an elevation of $56.3 \mathrm{~m}$ is inferred for the slip surface, $0.5 \mathrm{~m}$ deeper than would be expected from the slip surface identified through changes in tip resistance. These observations suggest that this additional penetration distance is required to elevate pore pressures to values indicative of the intact soil behaviour. 
Fig. 16. Comparison of CPT traces in intact soil (CPT12-05) and downslope of crest scarp of landslide (CPT12-08) illustrating slip surface detection from strength parameters, $u_{2}$ pore pressure, and calculation of remolding index.

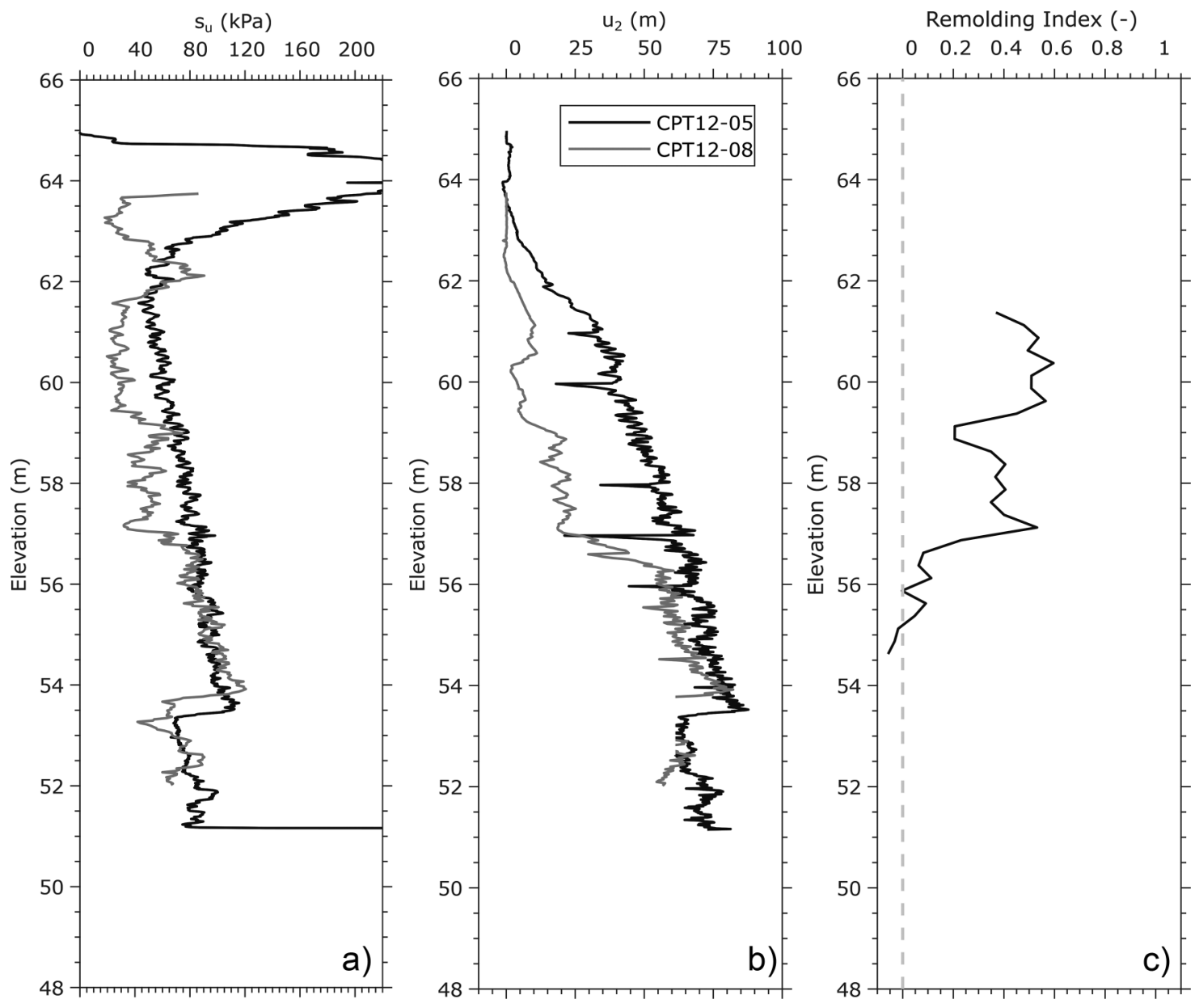

Given that only $1.2 \mathrm{~m}$ of vertical displacement has occurred in the CPT trace above the slip surface with respect to the intact profile, the degree of remolding can be calculated following the remolding index, $R$, proposed by Tavenas et al. (1983) and interpreted here in terms of in situ measurements:

$$
\text { (5) } \quad R=\frac{s_{\mathrm{u}}-s_{\mathrm{ux}}}{s_{\mathrm{u}}-s_{\mathrm{ur}}} \times 100
$$

where $s_{\mathrm{u}}$ is the intact undrained strength at a given elevation, $s_{\mathrm{ux}}$ is the undrained strength of the partially remolded soil at the same original elevation, and $s_{\mathrm{ur}}$ is the remolded strength from a laboratory fall cone (found to be $1 \mathrm{kPa}$ for the upper clay using fully remolded grab samples taken from the failure bowl). In this definition, the remolding index will be $0 \%$ in intact clay and $100 \%$ in fully remolded clay. To minimise the effect of variability of $s_{\mathrm{u}}$ and $s_{\mathrm{ux}}$ with depth on the calculation, mean values were taken in $0.25 \mathrm{~m}$ increments of depth for use to calculate the remolding index.

The profile of remolding index calculated for the upper clay is shown in Fig. 16c. Given the variability of CPT tip resistance in the crust layer observed between cone holes, this layer was not included in the comparison. This indicates that the shear deformation associated with the progressive retrogression at the slope at this location has resulted in the soil becoming approximately $50 \%$ remolded.

The location of the slip surface in the flank of the landslide is investigated through the comparison of cone hole 13-04 in the stable soil at the crest of the slope and hole 13-06 within the landslide mass (Fig. 17). This shows nominally identical response in terms of slip surface detection from the transition from remolded to intact shear strength and remolded to intact $u_{2}$ pore pressure response. Further, the calculation of remolding index illustrates that the soil in this portion of the landslide has experienced a similar degree of remolding as the location tested in 2012. The elevation of the slip surface identified in the CPT trace is plotted as an "X" marker in the tip resistance and pore pressure profiles of Figs. 14 and 15, confirming the presence of a failure plane with a strike following the crest scarp at a dip of $60^{\circ}$.

The calculation of the remolding index requires a comparison of the same soil layer before and after remolding and possible translation in the soil profile due to landslide movement. In the present study, the relatively homogeneous nature of the sensitive clay deposit combined with the small vertical deflection of the remolded soil mass minimises the need to infer the original elevation of the $s_{\mathrm{u}}$ profile of the remolded clay above the slip surface. While the portion of remolded CPT above the slip surface could have been translated vertically upwards in elevation by $1.2 \mathrm{~m}$ to conduct the calculation (i.e., to compare the remolded soil to the intact soil at its original elevation prior to the landslide), this offset does not appreciably change the calculated remolding index in the present study. In contrast, cases in which the vertical translation of the landslide mass between the original and remolded elevations is significant (e.g., $10 \mathrm{~m}$ vertical offset in cone tests for the Saint-Jude landslide described by Locat et al. 2017) would require a detailed interpretation of the failure mechanism to ensure the remolded 
Fig. 17. Comparison of CPT traces in intact soil (CPT13-04) and downslope of crest scarp of landslide (CPT13-06) illustrating slip surface detection from strength parameters, $u_{2}$ pore pressure, and calculation of remolding index.
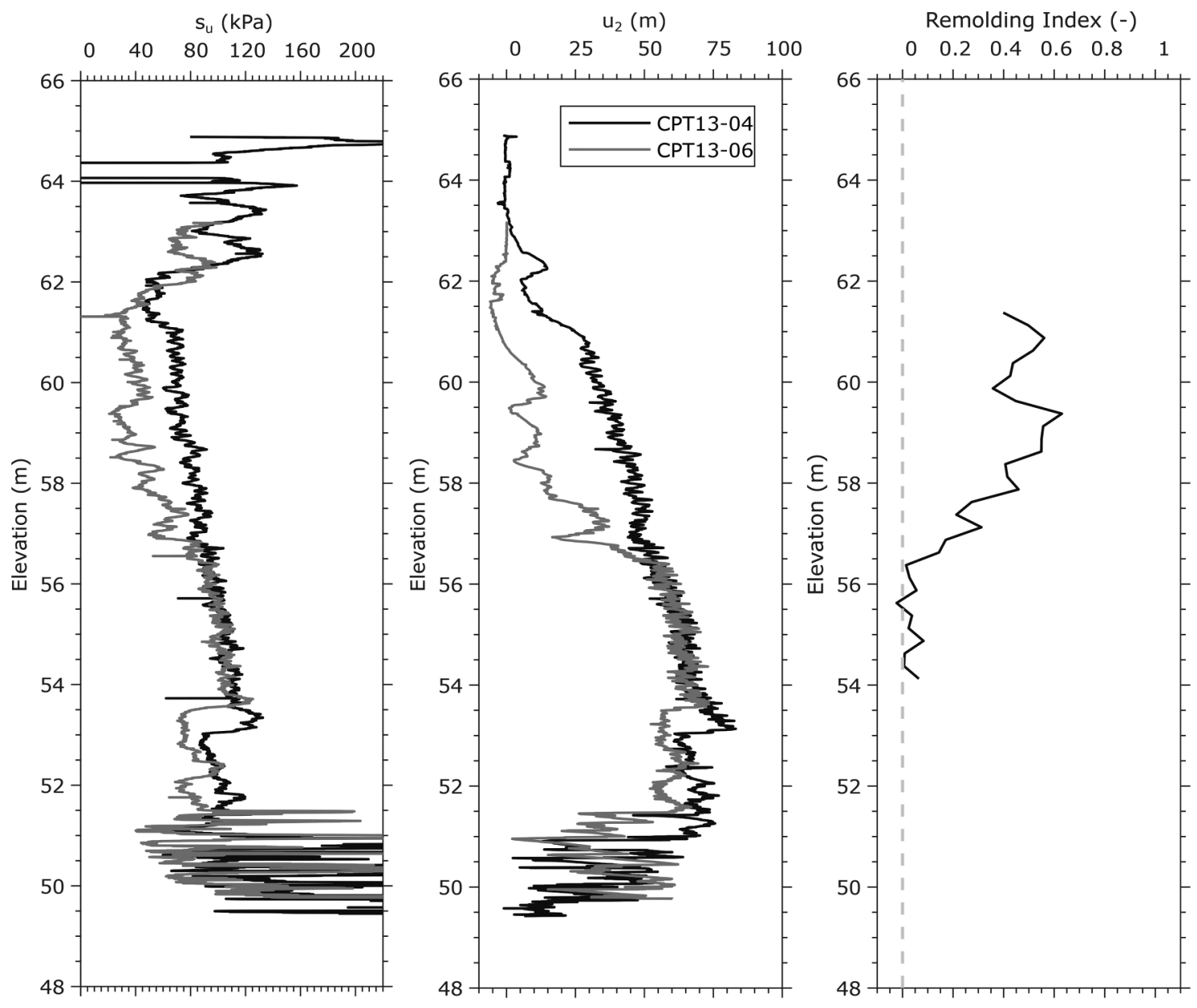

index correctly identifies and maps the corresponding soil locations in the profile before and after transport.

\section{Conclusions}

A multi-year CPT testing program was initiated at a landslide subject to episodic retrogression in Mud Creek, Ottawa, to further advance the use of cone penetration testing (CPT) for the investigation of sensitive clay landslides. Specifically, the work aimed to (i) quantify the effect of cone size on pore pressures generated by the penetration of four different sized cones; (ii) develop a frequency domain analysis of pore pressure data to support millimetricscale stratigraphic profiling and provide insights into the frequency content that may be lost if a cone is not fully saturated; and (iii) confirm whether a hand-operated mobile CPT could permit the quantification of the degree of remolding under progressive failure in metastable areas of a landslide where conventional tracked rigs are unable to gain access.

Four different sized cones $\left(2,5,10\right.$, and $\left.15 \mathrm{~cm}^{2}\right)$ were pushed to investigate the effect of cone size on parameters of relevance for landslide investigation in sensitive clays. The corrected total tip resistance and sleeve friction measured by the three different sized cones containing these sensors showed excellent visual agreement, with no trend based on cone size observed in the variability between cone holes. In contrast, measurements of pore pressure generated at the $u_{2}$ position were observed to vary considerably with cone size, with the magnitude of pore pressure response decreasing with cone size from $15,10,5$, to $2 \mathrm{~cm}^{2}$.
A new frequency domain approach to the analysis of dynamic pore pressure profiles was developed in which the signal content of the $u_{2}$ profile (i.e., spatial frequency of the $u_{2}$ response describing the transition between layers) using a fast Fourier transform (FFT). This approach illustrated that slight textural changes in the clay such as bands and varves are represented as a highfrequency response of the $u_{2}$ measurements from the penetrating cone, which are suppressed after remolding. Experiments using a purposefully poorly saturated cone illustrate the importance of a fully saturated cone, as the presence of air in the $u_{2}$ measurement system serves to act as a low-pass filter that eliminates the highfrequency content of the $u_{2}$ response required to observe these textural changes in the clays.

Finally, initial concerns over the low remolded strength of the sensitive clay to restrict the ability for screw anchors to generate a reaction force to resist cone penetration were observed to be unfounded. The mobile CPT rig permitted CPT tests to be performed through the entire thickness of the Champlain Sea deposit until refusal in the till at a penetration rate of $0.5 \mathrm{~cm} / \mathrm{s}$, a rate observed to yield nominally identical results to tests performed at the standard $2 \mathrm{~cm} / \mathrm{s}$. The ability to access portions of the site that are metastable enabled the direct comparison of soil within and adjacent to the slip surface at two different stages of retrogression. The elevation of the slip surface was clearly identified in the tip resistance as the point of transition between the remolded soil above the slip surface and the intact soil below the slip surface, whereas a further $0.5 \mathrm{~m}$ of penetration was required to elevate pore pressures to values indicative of the intact soil 
behaviour. The episodic nature of the retrogression resulted in a small increment of displacement, which allowed in situ measurements of shear strength of corresponding layers between the intact and remolded profiles to be compared to calculate degree of remolding using an in situ interpretation of Tavenas et al.'s (1983) remolding index. Despite the brittleness of the Champlain Sea Clay, this analysis indicates that the soil above the slip surface had only remolded to $50 \%$ of its drop to fully remolded strength, illustrating the large degree of deformation required to reach the fully remolded state. Furthermore, these findings raise the interesting proposition that the degree of remolding in a growing pre-failure extensional strain zone (quantified using closely spaced mobile-frame CPT tests in the direction of possible retrogression) could be linked to estimates of extensional strain (quantified from a similar network of surface displacement nodes to capture the in situ strain softening behaviour of sensitive clay slopes.

\section{Acknowledgements}

Financial support for the Mud Creek landslide study is gratefully acknowledged from ConeTec Site Investigations Ltd. and Natural Sciences and Engineering Research Council of Canada (NSERC) under the Discovery and Discovery Accelerator Supplement grant programs. The authors acknowledge the partnership of the National Capital Commission and the enthusiastic support of Eva Katic to gain academic access to Greenbelt lands to gain a better understanding of the long-term behaviour of landslides in the Green's Creek and Mud Creek watersheds. The support, expertise, and assistance provided by Will McQueen, Bruce Miller, and Ethan Cargill during CPT testing is gratefully acknowledged.

\section{References}

Agaiby, S.S., and Mayne, P.W. 2018. Interpretation of piezocone penetration and dissipation tests in sensitive Leda clay at Gloucester test site. Canadian Geotechnical Journal, 55(12): 1781-1794. doi:10.1139/cgj-2017-0388.

Antevs, S. 1925. Retreat of the last ice-sheet in Eastern Canada. Memoir 146. Geological Survey of Canada, Ottawa, Ont.

Boulanger, R.W., and DeJong, J.T. 2018. Inverse filtering procedure to correct cone penetration data for thin-layer and transition effects. In Cone Penetration Testing 2018: Proceedings of the 4th International Symposium on Cone Penetration Testing (CPT'18), Delft, the Netherlands, 21-22 June 2018. Edited by M.A. Hicks, F. Pisanò, and J. Peuchen. CRC Press, London, UK. pp. 25-44.

DeJong, J.T., and Randolph, M.F. 2012. Influence of partial consolidation during cone penetration on estimated soil behavior type and pore pressure dissipation measurements. Journal of Geotechnical and Geoenvironmental Engineering, ASCE, 138(7): 777-788. doi:10.1061/(ASCE)GT.1943-5606.0000646.

DeJong, J., DeGroot, D., Yafrate, N., and Jakubowski, J. 2003. Detection of soil layering using a miniature piezoprobe. In Proceedings of Soil Rock America 2003, Boston, Mass., 23 June 2003.
DeJong, J., Yafrate, N., and Degroot, D. 2007. Design of a miniature piezoprobe for high resolution stratigraphic profiling. Geotechnical Testing Journal, 30(4): 1-11. doi:10.1520/GTJ100592.

Demers, D., Leroueil, S., and d'Astous, J. 1999. Investigation of a landslide in Maskinongé, Québec. Canadian Geotechnical Journal, 36(6): 1001-1014. doi:10.1139/ t99-069.

Fransham, P.B., and Gadd, N.R. 1977. Geological and geomorphological controls of landslides in Ottawa Valley, Ontario. Canadian Geotechnical Journal, 14: 531-539. doi:10.1139/t77-054.

Gadd, N.R. 1962. Surficial geology of the Ottawa area. 62-16. Geological Survey of Canada, Ottawa, Ont. doi:10.4095/108814.

Hird, C.C., and Springman, S. 2006. Comparative performance of $5 \mathrm{~cm}^{2}$ and $10 \mathrm{~cm}^{2}$ piezocones in a lacustrine clay. Géotechnique, 56: 427-438. doi:10.1680/ geot.2006.56.6.427.

Hird, C.C., Johnson, P., and Sills, G.C. 2003. Performance of miniature piezocones in thinly layered soils. Geotechnique, 53(10): 885-900. doi:10.1680/ geot.2003.53.10.885.

Hugenholtz, C.H., and Lacelle, D. 2004. Geomorphic controls on landslide activity in Champlain Sea clays along Green's Creek, Eastern Ontario, Canada. Géographie physique et Quaternaire, 58: 9-23. doi:10.7202/013108ar.

Johnson, W. 1917. Pleistocene and recent deposits in the vicinity of Ottawa, with a description of the soils. Memoir 101, No. 84. Geological Survey of Canada, Ottawa, Ont.

Locat, A., Locat, P., Demers, D., Leroueil, S., Robitaille, D., and Lefebvre, G. 2017. The Saint-Jude landslide of 10 May 2010, Quebec, Canada: investigation and characterization of the landslide and its failure mechanism. Canadian Geotechnical Journal, 54(10): 1357-1374. doi:10.1139/cgj-2017-0085.

Lunne, T., Robertson, P.K., and Powell, J.J.M. 1997. Cone penetration testing in geotechnical engineering. Blackie Academic and Professional, Great Britain.

Mayne, P.W. 2009. Geoengineering design using the cone penetration test. ConeTec Investigations Inc., Vancouver, B.C.

Mitchell, R.J., and Eden, W.J. 1972. Measured movements of clay slopes in the Ottawa area. Canadian Journal of Earth Sciences, 9(8): 1001-1013. doi:10.1139/ e72-084.

Mo, P.-Q. Marshall, A.M., and Yu, H.-S. 2016. Interpretation of cone penetration test data in layered soils using cavity expansion analysis. Journal of Geotechnical and Geoenvironmental Engineering. ASCE, 143(1): 04016084. doi:10.1061/ (ASCE)GT.1943-5606.0001577.

Rad, N.S., and Tumay, M. 1985. Pore-pressure response of the piezocone penetrometer. Geotechnical Testing Journal, 8(3): 125-131. doi:10.1520/GTJ10523J.

Robertson, P.K. 1990. Soil classification using the cone penetration test. Canadian Geotechnical Journal, 27(1): 151-158. doi:10.1139/t90-014.

Sangrey, D.A., and Paul, M.J. 1971. A regional study of landsliding near Ottawa. Canadian Geotechnical Journal, 8(2): 315-335. doi:10.1139/t71-026.

Tavenas, F., Flon, P., Leroueil, S., and Lebuis, J. 1983. Remolding energy and risk of slide retrogression in sensitive clays. In Proceedings of the Symposium on Slopes on Soft Clays, Linköping, Sweden, 8-10 March 1982. Swedish Geotechnical Institute (SGI) Report No. 17. pp. 423-454.

Teh, C.I., and Houlsby, G.T. 1991. Analytical study of the cone penetration test in clay. Géotechnique, 41: 17-34. doi:10.1680/geot.1991.41.1.17.

Torstensson, B.A. 1977. The pore pressure probe. Paper No. 34. Nordiske Geoteknisk Mote, Oslo.

Walker, J., and Yu, H.S. 2010. Analysis of the cone penetration test in layered clay. Géotechnique, 60(12): 939-948. doi:10.1680/geot.7.00153.

Williams, D.R., Romeril, P.M., and Mitchell, R.J. 1979. Riverbank erosion and recession in the Ottawa area. Canadian Geotechnical Journal, 16(4): 641-650. doi:10.1139/t79-074.

Whittle, A., Sutabutr, T., Germaine, J., and Varney, A. 2001. Prediction and interpretation of pore pressure dissipation for a tapered piezoprobe. Géotechnique, 51(7): 601-617. doi:10.1680/geot.2001.51.7.601. 